Trabajos de Prehistoria

48, 1991, pp. 103-134

\title{
MATERIALES DE LA CUEVA DE SON BAUZA (MALLORCA)
}

\author{
POR \\ FRANCISCO LUIS FRONTAN FERNANDEZ (*)
}

RESUMEN El yacimiento arqueológico de Son Bauzá (Mallorca) es una cueva natural utilizada como lugar de enterramiento en época prerromana. Descubierta en 1929, fue parcialmente excavada y expoliada y desde entonces aparece citada abundantemente en la bibliografía entre las principales necrópolis de la Edad del Hierro mallorquina (Talayótico III o Pos-Talayótico, según los autores). Sin embargo, gran parte de los materiales arqueológicos conservados de este yacimiento permanecían inéditos o publicados con imprecisión. Presentamos ahora el conjunto de todos ellos así como de la información existente en cuanto al contexto en que aparecieron.

ABSTRACT The archaeological site of Son Bauzá (Majorca) is a natural cave, used as a burial site in the Preroman Period. Discovered in 1929, it was partially excavated and robbed and since then, it has often been cited in the bibliography of the main cemeteries of the Iron Age in Majorca (Talayotic III or Post-Talayotic, according to the authors). However, most of the archaeological materials preserved from this site remained unpublished or partially published. We now present all of these materials along with the available information about the context in which they appeared.

Palabras clave Ajuar funerario. Necrópolis. Cueva. Son Bauzá. Pos-Talayótico. Edad del Hierro. Mallorca.

Key words Grave goods. Necropolis. Cave. Son Bauza. Post-Talayotic. Iron Age. Majorca.

\section{INTRODUCCION}

El yacimiento arqueológico de Son Bauzá es una cueva natural situada junto a la finca del mismo nombre, cerca de Establiments (Palma de Mallorca). El acceso se realiza por la carretera local de Palma a Esporles; poco antes de llegar al $\mathrm{Km}$. 10 hay un camino de tierra a la derecha que conduce a una casa a cuya espalda se sitúa la cueva, en la ladera meridional del monte, a unos 150 m. de altura sobre el nivel del mar.

Las coordenadas geográficas del yacimiento son: $39^{\circ} 38^{\prime} 35^{\prime \prime}$ de latitud Norte y $6^{\circ} 17^{\prime} 58^{\prime \prime}$ de longitud Este del Meridiano de Madrid, según la hoja № 698 del Mapa Topográfico Nacional, escala 1: 50.000, editado por el Instituto Geográfico y Catastral en 1964.

(*) Licenciado en Prehistoria y Arqueologia por la Universidad Autónoma de Madrid. 


\section{HISTORIA DE LA INVESTIGACION}

El descubrimiento de la cueva de Son Bauzá como yacimiento arqueológico data de 1929 (1) cuando al intentar la explotación de unas calizas marmóreas (2) salen a la luz los primeros restos arqueológicos. El acontecimiento atrajo pronto el interés de eruditos aficionados a la arquelogía y coleccionistas de antigüedades. Divulgado el hallazgo, el Museo Regional de Artá envió una «Comisión de Investigaciones», dirigida por Luis R. Amorós, con el fin de realizar excavaciones. Estas fueron pronto suspendidas - duraron tan sólo tres días-, ya que el propietario de la finca homónima de la cueva retiró el permiso dado al Museo. A partir de entonces, son varios aficionados y coleccionistas los que se dedican a la búsqueda de objetos en el yacimiento: Antonio Mulet, Lluis Ferbal, Andreu Crespi, Josep Costa y Vicens Juan Serra.

El primero de ellos, Antonio Mulet, formó una colección particular que exhibía en su casamuseo, llamada Ca'n Mulet, del barrio de Génova en Palma de Mallorca; colección que posteriormente fue cedida en parte al Museo de Lluc, donde puede contemplarse en la actualidad.

Los otros coleccionistas llevaron sus hallazgos al Museo de la Sociedad Arqueológica Luliana, en Palma (3). Las colecciones que formaban dicho Museo pasaron con posterioridad a engrosar los fondos del Museo de Mallorca, en donde se encuentran depositados actualmente.

De esta forma, entre 1929 y 1930 se excava el yacimiento hasta el piso de roca, vaciándolo de su contenido y perdiendo casi la totalidad de la información arqueológica al destruirse la estratigrafía así como - presumiblemente-, gran número de objetos y materiales poco atractivos para los coleccionistas.

De la excavación dirigida por Luis R. Amorós quedan los materiales guardados en el Museo de Artá y su breve artículo de 1929. En el Museo de Lluc también se conserva un curioso fragmento de cerámica con decoración incisa procedente de Son Bauzá que fue donado por un particular del que desconocemos más detalles. Por último, se ha citado la colección Quetglas, en Valdemosa, entre las que tienen materiales de Son Bauzá (Font Obrador, 1970: 396); pero de dicha colección no nos ha sido posible conocer ni su ubicación ni su contenido, como tampoco confirmar o desmentir su existencia.

(1) Los dos primeros testimonios bibliográficos sobre el tema, los artículos del P. Lorenzo Lliteras y de Luis R. Amorós, no especifican la fecha del descubrimiento, pero teniendo en cuenta que el primero se pubicó como artículo periodístico - suponemos que de actualidad-, el 29 de mayo de 1929 y que el segundo está fechado en junio del mismo año de 1929, hemos dado en suponer que el descubrimiento pudo producirse en los primeros cinco meses de dicho año. Más tarde, Amorós (1933), en una relación de objetos de Son Bauzá donados al Museo de la Sociedad Arqueológica Luliana de Palma, escribe: "excavació efectuada l'any 1929w. Puede ser que se refiera a la breve excavación dirigida por él a cuenta del Museo Regional de Artá o bien a la actividad de los coleccionistas y aficionados que estuvieron en el yacimiento una vez retirado el permiso al Museo de Artá: si es lo segundo, nos extraña que use el término «excavación, sin más, para tales actividades. Sea como fuere, no hay razón para suponer el descubrimiento en fecha anterior a los primeros meses de 1929. Es posible que las actividades de los coleccionistas y aficionados se alargaran durante el resto del año 1929 e incluso en 1930, ya que en una de las piezas de cerámica de Son Bauzá del Museo de la Sociedad Arqueológica Luliana - hoy en el Museo de Mallorca ( ${ }^{\circ}$ de inventario 8973)- hay una etiqueta en la que se lee: «Excavación en Sa Cova de So'n Bauzá (Establiments) 1930.... Por su parte, C. Veny (1968: 235) y B. Font Obrador (1970. 395) también dan fecha de 1929, como Amorós. Sin embargo, M." Dolores Garralda (1970: 93), en su estudio de restos humanos, dice que ufueron hallados por Luis Amoros (1927) en el yacimiento de Son Bauzáw. A falta de datos que avalen esta última fecha, consideramos más probable la ya comentada de 1929 como la del descubrimiento del yacimiento en cuestión.

(2) Esto es lo que afirma Amorós (1929: 290): lo mismo dicen C. Veny (1969: 235) y B. Font Obrador (1970: 395). Otras versiones señalan que el hallazgo se produjo de forma fortuita por un agricultor al remover el piso de la cueva buscando abono para sus tierras (Bauzá Rullán, 1946: 204).

(3) Según consta en una vieja etiqueta pegada al interior de un vaso cerámico -ya comentado en nota 1- del Museo de Mallorca ( $\mathbf{N}^{\circ}$ de inventario 8973) que forma parte del depósito hecho por la Sociedad Arqueológica Luliana: «Excavación en Sa Cova de So'n Bauzá (Establimenst) 1930. Donativo: L. Ferbal, A. Crespí, J. Costa y V. Juan Serra». Por otra parte, en un artículo titulado «Museo de la Societat Arqueológica Luliana. Relació d'objectes ingresats durant el quart trimestre d'enguany» (Amorós, 1933: 252), se citan también a los cuatro anteriores como donantes de una serie de objetos arqueológicos procedentes de la «excavació efectuada l'any 1929 . Según lo expuesto, parece que fue en 1929 y quizás también en 1930 cuando estos coleccionistas excavaron en Son Bauzá en busca de antigüedades. 


\section{DESCRIPCION DE LA CUEVA}

La cueva de Son Bauzá, como ya hemos señalado anteriormente, es una cavidad natural situada a media ladera de un monte que apenas alcanza los 267 metros de altura sobre el nivel del mar, estando la entrada de la cueva a unos 150 metros de altura sobre dicho nivel.

Una gran grieta de paredes abruptas señala el comienzo de la cueva que penetra horizontalmente hacia el interior del monte, alcanzando una longitud máxima de 34 metros con una orientación aproximada de Sur a Norte. En el umbral de la cueva, una pared de mampostería y una puerta de construcción reciente cierran el acceso al interior ya que la cueva ha venido utilizándose como refugio de ganado y almacén de enseres agrícolas.

La planta de la cueva (Fig. 1) presenta una acusada angostura hacia su mitad que la divide en dos zonas de parecidas dimensiones, ambas cubiertas por una bóveda de irregular curvatura.

La zona más próxima a la entrada está dividida longitudinalmente por un espolón rocoso de poca altura que se alarga hasta el centro de la estancia en donde una columna contribuye de forma natural al sostenimiento de la bóveda. Las diferencias de nivel del suelo en esta zona son el fruto de las excavaciones en busca de restos arqueológicos y la extracción de piedra. Durante la excavación dirigida por Amorós se practicó una zanja de más de un metro de profundidad (Amorós, 1929: 291). A estas remociones hay que añadir una trinchera de unos 15 metros de larga y cinco de profundidad practicada en la entrada de la cueva con fines paleontológicos pero sin relación con la necrópolis (Bauzá Rullán, 1946).

\section{LA ESTRATIGRAFIA ARQUEOLOGICA}

Hemos de hacer obligada referencia a la bibliografía para encontrar algunos datos sobre el particular, ya que en la actualidad el piso de la cueva ha perdido todo rastro de la cobertura que constituían los enterramientos y los ajuares depositados con éstos. Por esta razón incluimos aquí las observaciones que pudo hacer L. R. Amoros en la zona S.E. de la cueva: "Practicada una zanja de más de un metro de profundidad, en el corte producido pudieron apreciarse con perfecta claridad dos niveles plenamente diferenciados conteniendo ambos material arquelógico. El nivel superior de un grueso de 0,40 a 0,50 m. completamente removido, estaba formado por una regular cantidad de piedras y tierra de donde salieron varios fragmentos de tejas romanas, de ánforas y de cerámica típica romana, faltando en absoluto restos humanos $y$ apareciendo en cambio algunos huesos de animales (...) Debajo, a continuación de este nivel y separado del mismo por un enlosado de piedras no muy grandes e irregulares, aparecia otro ofreciendo propiamente yacimiento intacto de un grueso que oscilaba entre 0,35 y 0,30 m. de cenizas blancuzcas, abundancia de huesos humanos quemados $y$ restos de madera carbonizada». Los objetos que aparecieron en este nivel "suelen aparecer mezclados sin orden algunon (Amorós, 1929: 291 y ss).

La disposición del yacimiento, aunque de forma concisa, es corroborada por L. Lliteras: «...después de una capa superficial, y bien, separada de ésta por las típicas losas, viene la de enterramientos incinerados..." (Lliteras, 1929).

También J. Cañigueral da algunos detalles: «... en la cueva de Son Bauzá de Establiments (Palma), según me dijo D. José Colominas, apareció un fragmento de ollita con muñón perforado que tiene la particularidad de tener adornos de arquitos en hileras verticales, incisos con la sección de una caña. Esta cueva de Son Bauzá ha dado mucho material talayótico y romano, pero el fondo era argárico 


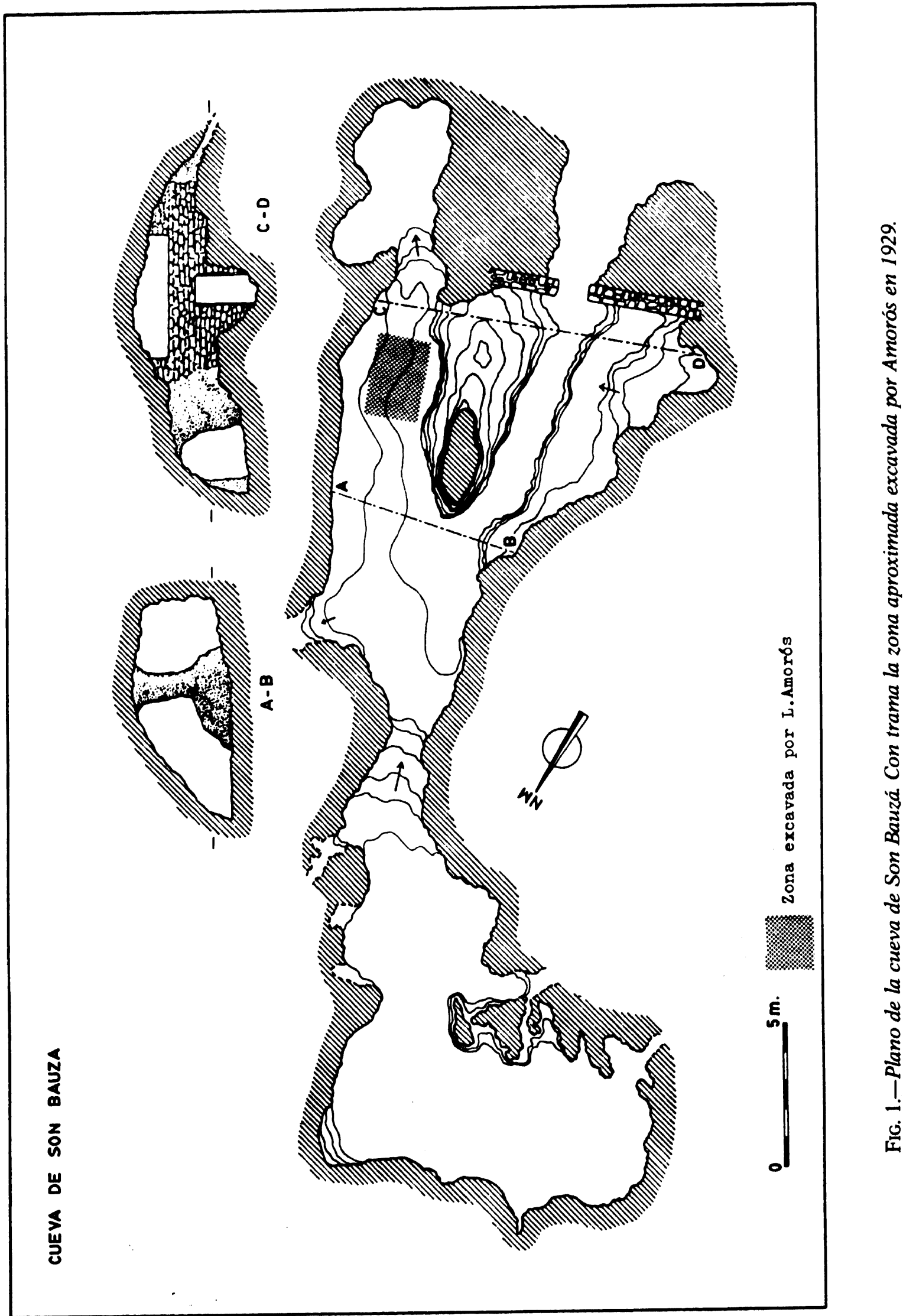

T. P., 1991, $\mathrm{n}^{9} 48$

(c) Consejo Superior de Investigaciones Científicas

http://tp.revistas.csic.es Licencia Creative Commons 3.0 España (by-nc) 
primitivo y de él salió la ollita; más abajo ha aparecido cuaternario como Myotragus balearicus, pero sin huellas humanas" (Cañigueral, 1952: 8) (4).

\section{LOS MATERIALES}

\section{INVENTARIO DE MATERIALES CONSERVADOS EN LOS MUSEOS *}

* «Museo Arqueológico de Artá, Museo de Lluc (colección A. Mulet) y Museo de Mallorca (Colección Sociedad Arqueológica Luliana)

\begin{tabular}{|c|c|c|c|c|c|c|c|c|c|}
\hline $\mathbf{N}^{\mathbf{2}}$ & $\begin{array}{l}\text { TIPO DE } \\
\text { OBJETO } \\
\end{array}$ & MATERIA & MUSEO & $\begin{array}{l}\text { No INVEN. } \\
\text { TARIO }\end{array}$ & $\mathbf{N}^{2}$ & $\begin{array}{l}\text { TIPO DE } \\
\text { OBJETO } \\
\end{array}$ & MATERIA & MUSEO & $\begin{array}{c}\text { No INVEN- } \\
\text { TARIO } \\
\end{array}$ \\
\hline \multirow[t]{2}{*}{1} & Puñal de & & & & 33 & Varilla & $\mathrm{Cu} /$ Bronce & Artá & 323 \\
\hline & antenas & $\mathrm{Fe}$ & Artá & 333 & 34 & Varilla & $\mathrm{Cu} /$ Bronce & Artá & 324 \\
\hline 2 & Espada & $\mathrm{Fe}$ & Lluc & - & 35 & Varilla & $\mathrm{Cu} /$ Bronce & Artá & 325 y 327 A \\
\hline 3 & Espada & $\mathrm{Fe}$ & Lluc & - & 36 & Varilla y & & & \\
\hline 4 & Espada & $\mathrm{Fe}$ & Artá & - & & Cadena & $\mathrm{Cu} /$ Bronce & Lluc & - \\
\hline 5 & Espada & $\mathrm{Fe}$ & Artá & - & 37 & Disco & $\mathrm{Cu} /$ Bronce & Artá & 317 \\
\hline 6 & Espada & $\mathrm{Fe}$ & Artá & - & 38 & Disco & $\mathrm{Cu} /$ Bronce & Artá & 316 \\
\hline 7 & Espada & $\mathrm{Fe}$ & Artá & - & 39 & Disco & $\mathrm{Cu} /$ Bronce & Artá & 319 \\
\hline 8 & Cuchillo & $\mathrm{Fe}$ & Lluc & $2 / 138$ & 40 & Disco & $\mathrm{Cu} /$ Bronce & Artá & 310 \\
\hline 9 & Cuchillo & $\mathrm{Fe}$ & M. Mall & - & 41 & Disco & $\mathrm{Cu} /$ Bronce & M. Mall. & 8954 \\
\hline 10 & Brazalete & $\mathrm{Fe}$ & Artá & 339 & 42 & Disco & $\mathrm{Cu} /$ Bronce & M. Mall. & 8952 \\
\hline 11 & Brazalete & $\mathrm{Fe}$ & Lluc & - & 43 & Disco & $\mathrm{Cu} /$ Bronce & Artá & 320 \\
\hline 12 & Brazalete & $\mathbf{F e}$ & Lluc & - & 44 & Disco & $\mathrm{Cu} /$ Bronce & Artá & 321 \\
\hline 13 & Brazalete & $\mathrm{Fe}$ & Artá & 3... (?) & 45 & Disco & $\mathrm{Cu} /$ Bronce & M. Mall. & 8964 \\
\hline 14 & Brazalete & $\mathrm{Fe}$ & Artá & 348 & 46 & Disco & $\mathrm{Cu} /$ Bronce & Lluc & $2 / 180$ \\
\hline 15 & Brazalete & $\mathbf{F e}$ & Artá & 348 & 47 & Disco & $\mathrm{Cu} /$ Bronce & M. Mall. & 8950 \\
\hline 16 & Brazalete & $\mathrm{Fe}$ & Artá & 347 & 48 & Disco & $\mathrm{Cu} /$ Bronce & M. Mall. & 8951 \\
\hline 17 & Brazalete & $\mathrm{Fe}$ & Lluc & - & 49 & Disco & $\mathrm{Cu} /$ Bronce & Lluc & 2/180 Bis \\
\hline 18 & Brazalete & $\mathrm{Fe}$ & Lluc & - & 50 & Punta de lanza & Bronce & Lluc & - \\
\hline 19 & Brazalete & $\mathrm{Fe}$ & Artá & 345 & 51 & Punta de lanza & Bronce & Lluc & - \\
\hline 20 & Brazalete & $\mathrm{Fe}$ & M. Mall. & 8963 & 52 & Punta de lanza & Bronce & Lluc & - \\
\hline 21 & Brazalete & $\mathrm{Fe}$ & M. Mall. & 8955 & 53 & Punta de venablo & Bronce & M. Mall. & 8957 \\
\hline 22 & Brazalete & $\mathrm{Fe}$ & M. Mall. & 8962 & 54 & Campanilla & $\mathrm{Cu} /$ Bronce & M. Mall. & 8960 \\
\hline 23 & Brazalete & $\mathrm{Fe}$ & Artá & $3 \ldots(?)$ & 55 & Campanilla & $\mathrm{Cu} /$ Bronce & M. Mall. & 8959 \\
\hline 24 & Brazalete & $\mathrm{Fe}$ & Artá & 351 & 56 & Campanilla & $\mathrm{Cu} /$ Bronce & M. Mall. & 8958 \\
\hline 25 & Brazalete & $\mathbf{F e}$ & Artá & 340 & 57 & Campanilla & $\mathrm{Cu} /$ Bronce & Artá & 335 \\
\hline 26 & Brazalete & $\mathrm{Fe}$ & Artá & 350 & 58 & Campanilla & $\mathrm{Cu} /$ Bronce & Artá & 336 \\
\hline 27 & Brazalete & $\mathrm{Fe}$ & Artá & 346 & 59 & Campanilla & $\mathrm{Cu} /$ Bronce & Artá & 334 \\
\hline 28 & Brazalete & $\mathrm{Fe}$ & Artá & - & 60 & Campanilla & $\mathrm{Cu} /$ Bronce & Artá & 333 \\
\hline 29 & Brazalete & $\mathrm{Fe}$ & Artá & - & 61 & Recipiente & $\mathrm{Cu} /$ Bronce & M. Mall. & 8972 \\
\hline 30 & Varilla & Ju/Bronce & Artá & 322 & 62 & Fíbula & $\mathrm{Cu} /$ Bronce & M. Mall. & 8949 \\
\hline 31 & Varilla & $\mathrm{Cu} /$ Bronce & Artá & 326 & 63 & Cuenta de & & & \\
\hline 32 & Varilla & $\mathrm{Cu} /$ Bronce & Artá & $327 \mathrm{~B}$ & & collar & Vidrio & M. Mall. & 8966 y 8967 \\
\hline
\end{tabular}

(4) El Myotragus balearicus fue identificado por primera vez, en 1909, por Miss Dorothea Bate, del British Museum. Este extraño, poco conocido y raramente evolucionado animal, es un miembro aberrante de los Nemorfaedinos pertenecientes al grupo Antilopino; y aparece como el mayor más abundante entre los mamíferos prehistóricos que habitaron las Baleares desde el Pleistoceno en adelante. Parecen existir indicios razonables para suponer que este animal fue contemporáneao de los primeros habitantes de Mallorca, que incluso pudieron haber intentado domesticarlo y que su desaparición está relacionada con la presión cinegética a que fue sometido. 


\begin{tabular}{|c|c|c|c|c|c|c|c|c|c|}
\hline $\mathbf{N}^{\mathbf{2}}$ & $\begin{array}{l}\text { TIPO DE } \\
\text { OBNETO }\end{array}$ & MATERIA & MUSEO & $\begin{array}{c}\text { Ne INVEN- } \\
\text { TARIO }\end{array}$ & $\mathbf{N}^{\mathbf{N}}$ & $\begin{array}{l}\text { TIPO DE } \\
\text { OBNETO }\end{array}$ & MATERIA & MUSEO & $\begin{array}{l}\text { Ne INVEN. } \\
\text { TARIO }\end{array}$ \\
\hline $\begin{array}{l}64 \\
65 \\
66 \\
67 \\
68\end{array}$ & $\begin{array}{l}\text { Cuenta de } \\
\text { collar } \\
\text { Cuenta de } \\
\text { collar } \\
\text { Cuenta de } \\
\text { collar } \\
\text { Cuenta de } \\
\text { collar } \\
\text { Cuenta de } \\
\text { collar } \\
\text { Cuenta de } \\
\text { collar } \\
\text { Fragmento } \\
\text { collar } \\
\text { Fragmento } \\
\text { collar } \\
\text { Colgante }\end{array}$ & $\begin{array}{l}\text { Vidrio/Fe } \\
\mathrm{Cu} / \text { Bronce }\end{array}$ & $\begin{array}{l}\text { M. Mall. } \\
\text { M. Mall. } \\
\text { M. Mall. }\end{array}$ & $\begin{array}{c}8966 \text { y } 8967 \\
" \\
"\end{array}$ & $\begin{array}{l}79 \\
80 \\
81 \\
82 \\
83 \\
84 \\
85 \\
86 \\
87\end{array}$ & $\begin{array}{l}\text { Cuenta de } \\
\text { collar } \\
\text { Punzón } \\
\text { Punzón (?) } \\
\text { Aro } \\
\text { Espiral } \\
\text { Aro }\end{array}$ & $\begin{array}{l}\text { Cerámica } \\
\text { Cerámica } \\
\text { Cerámica } \\
\text { Cerámica } \\
\text { Cerámica } \\
\text { Hueso } \\
\text { Hueso } \\
\text { Hueso } \\
\text { Hueso }\end{array}$ & $\begin{array}{c}\text { M. Mall. } \\
\text { M. Mall. } \\
\text { M. Mall. } \\
\text { Artá } \\
\text { Artá } \\
\text { Artá } \\
\text { Lluc } \\
\text { M. Mall. } \\
\text { M. Mall. } \\
\text { M. Mall. } \\
\text { M. Mall. } \\
\text { Artá } \\
\text { Artá } \\
\text { Artá } \\
\text { Artá }\end{array}$ & $\begin{array}{c}8966 \\
8956 \\
8961 \\
- \\
329 \\
100,328 \text { A } \\
328 \text { B } \\
- \\
8973 \\
8970 \\
8971 \\
8953 \\
356 \\
356 / \mathrm{A} \\
356 / \mathrm{C} \\
356 /(?)\end{array}$ \\
\hline
\end{tabular}

\section{DESCRIPCION DE MATERIALES}

\section{Puñal de antenas (№ 1)}

Se conocen en Mallorca al menos ocho ejemplares de puñales y espadas de hierro con empuñadura de antenas que se pueden dividir, según Fernández-Miranda en dos grupos de distintas cronologías: en el primero y más antiguo sitúa los ejemplares de Son Bauzá, Son Real, Bóquer y Cometa dels Morts, con una cronología en torno al siglo VI a. de $\mathbf{C}$., coincidiendo en esto con $\mathbf{M}$. Tarradell y las considera anteriores a los tipos con antenas de hierro de la Península Ibérica (Fernández-Miranda, 1978: 283-285, fig. 69).

El segundo grupo, más reciente, lo constituyen las espadas de Son Gallard, Es Morro y Son Matge, esta última hallada en un nivel de siglo III a. de C. (5).

\section{Espada de doble filo ( $\left.\mathrm{N}^{\circ} 2\right)$}

Esta hoja de espada, con doble filo y sección lenticular, tiene un espiga para el enmangue de sección redonda, característica que la diferencia de los tipos de espada de dos filos conocidos en Baleares, que terminan en una lengüeta más o menos larga con remaches (6). No es improbable que la hoja de Son Bauzá fuera del tipo con empuñadura de antenas, similar a la de Son Gallard antes citada.

(5) Para estas espadas puede consultarse: Fernández-Miranda, 1978; Font Obrador, 1970; Veny, 1947 y Waldren, 1982.

(6) Se conocen de este tipo un ejemplar incompleto de la Cometa dels Morts (Veny, 1947, 56; fig. 25 (4) y Veny, 1950: 325, fig. 4 (3-4). Y otro completo de la cueva de Massana (Veny, 1982: fig. 196).

\section{T. P., 1991, $\mathrm{n}^{2} 48$}



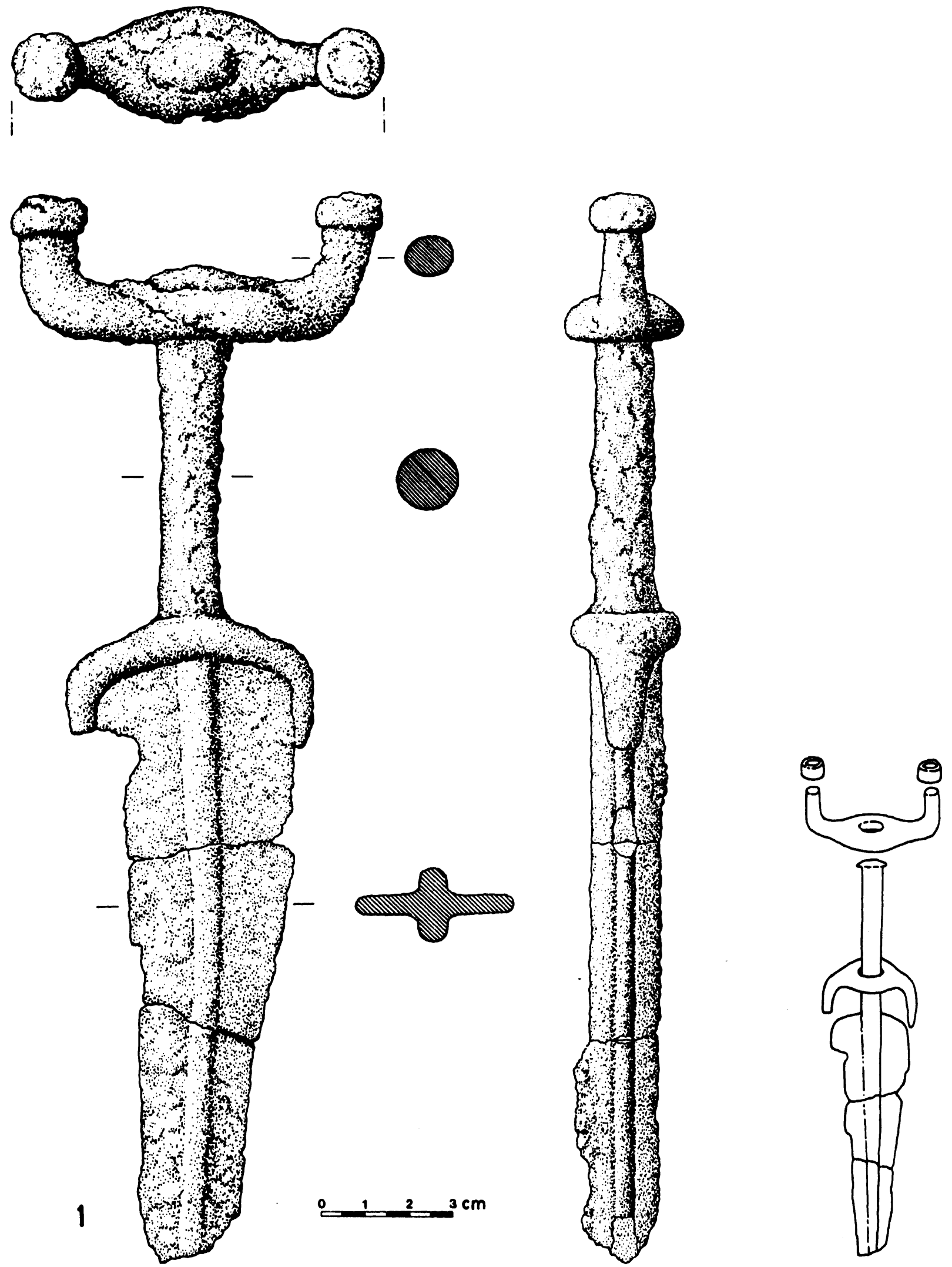

FIG. 2.-Puñal de antenas de hierro. A la derecha posible despiece del puñal.

T. P., $1991, \mathrm{n}^{9} 48$ 

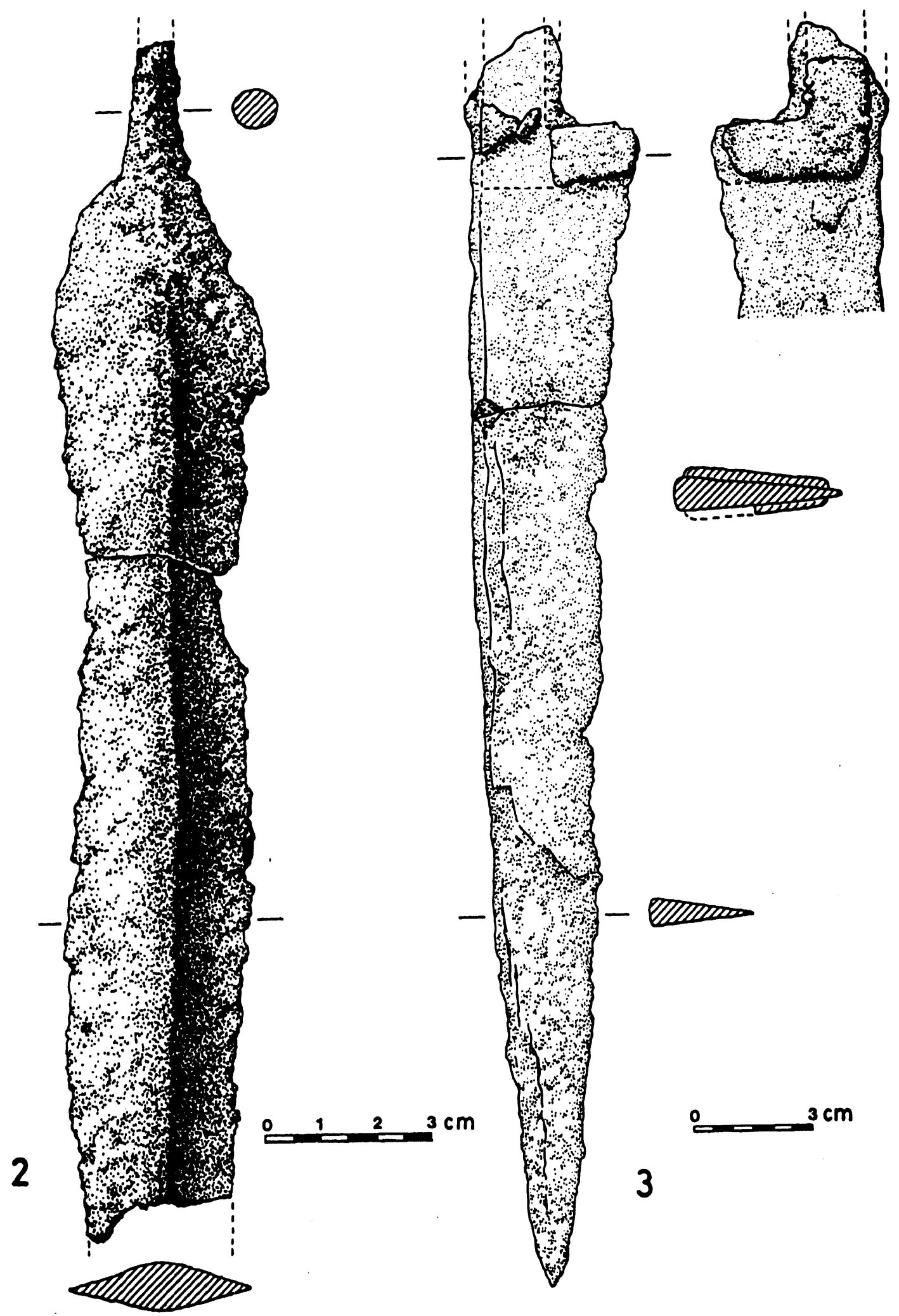

Fic. 3.-Espadas de hierro.

\section{T. P., 1991, $\mathrm{n}^{2} 48$}

(c) Consejo Superior de Investigaciones Científicas Licencia Creative Commons 3.0 España (by-nc) 


\section{Espadas afalcatadas (№ 3 a 7)}

En Mallorca, mucho menos en Menorca, es frecuente la aparición dentro de ajuares funerarios de espadas de hierro con un solo filo. Se caracterizan por tener la hoja ligeramente arqueada y triangular, con el filo en la parte interior a modo de guadaña. La empuñadura es una simple prolongación, como lengüeta más o menos ancha, del dorso de la hoja; con uno o varios remaches dispuestos en línea y a veces en «L" que sobresalen por ambos lados con la misión de sujetar unas cachas de las que desconocemos su forma completa y el material de que estaban hechas. A este tipo de espada, cuyas dimensiones rondan los $50 \mathrm{~cm}$. se le denomina falcata baleárica (7). De Son Bauzá se han conservado dos fragmentos de la parte superior de la hoja con el arranque de la empuñadura y remaches; dos fragmentos más de hoja y un ejemplar con la hoja entera y parte de la empuñadura con cachas metálicas en forma de «L", si bien esta última tiene menores dimensiones.

A la hora de buscar paralelos e influencias para este tipo de armas fuera de Mallorca y Menorca no parece que puedan considerarse en tal sentido los cuchillos púnicos de la vecina Ibiza. Estos son afalcatados, con mango recto o acabados en una estilizada cabeza de pato, y no superan los $20 \mathrm{~cm}$. de longitud (Vives y Escudero, 1917: 57, lám. XIV y 63, lám. XVIII, 7). Las reducidas dimensiones de los cuchillos curvos y afalcatados, de uso muy generalizado en la Península, es el principal inconveniente para establecer comparaciones, aunque los parecidos formales sean grandes con las armas insulares, como sucede con los tres cuchillos de hierro afalcatados del sepulcro de "Los Espleters" (Salzadella, Castellón), datado hacia el siglo IV a. de C. (Almagro Basch, 1975: 200), o el gran cuchillo afalcatado de la cueva de Montgó (Jávea, Alicante) (Almagro Gorbea, 1978: fig. 12).

Por otra parte, si consideramos las armas baleares respecto a las falcatas ibéricas, vemos que las diferencias tipológicas y estructurales son notables. Si las ibéricas fueron el modelo que inspiró a las baleáricas, hay que ver en estas últimas una imitación local muy rudimentaria y de peor calidad. En este sentido no hay que olvidar que en Mallorca se ha constatado la presencia de sendos ejemplares de falcata ibérica en los yacimientos de Sa Mola y Cometa dels Morts, en esta última conviviendo con los modelos baleáricos y con espadas de antenas (Veny, 1947: 55 y 1982: 351).

Lo cierto es que las denominadas falcatas baleáricas son un grupo de armas con características bastante homogénas que podemos considerar perfectamente como un desarrollo local a partir de alguno de los tipos de espadas utilizadas en el Mediterráneo, bien sea la machaira o kopis griega, la falcata ibérica, o tal vez una derivación de los cuchillos púnicos. Con esto, la cronología de las falcatas baleáricas difícilmente podría remontar el siglo IV a. de C., siendo lo mas probable que su auge coincida con las épocas de mayor participación de los mercenarios baleares en los ejércitos cartagineses.

\section{Cuchillos (№ 8 y 9)}

Los cuchillos de hierro no suelen estar entre los objetos más abundantemente documentdos en los yacimientos talayóticos en comparación a las otras armas. Ello es debido principalmente no a su rareza, sino más bien a que por sus características son de más difícil conservación en el medio ambiente que caracteriza las necrópolis en que aparecen. Al ser de hierro, pequeños y relativamente delgados, con frecuencia aparecen como simples fragmentos informes completamente corroídos que apenas dejan adivinir su pertenencia a una hoja de un solo filo, confundidos a veces con fragmentos de espada afalcatada.

En Mallorca conocemos los dos ejemplares casi completos de Son Bauzá, estando documentados algunos ejemplares en Son Matge (Waldren, 1982: 424, fig. 141) y otros cuatro, dudosos, en Son Taixaquet (Enseñat Enseñat, 1981: 117). En Menorca se documentan tres ejemplares de la Cova

(7) Hay constancia de hallazgos de estas espadas o restos de ellas en, al menos, once yacimientos de Mallorca: Cometa dels Morts, Son Maiol, Son Matge, Es Morro, Sa Cova, Son Real, Bóquer, Sa Mola, Almallutx, Massana, Cova Monja, Son Bosc y Son Maimó. En Menorca: Cales Coves (cuevas № XIX, XLV, XLVIII, LIV, LVII) y Sa Regana dels Cans (cueva No VI).

$$
\text { T. P., 1991, } \mathrm{n}^{\circ} 48
$$



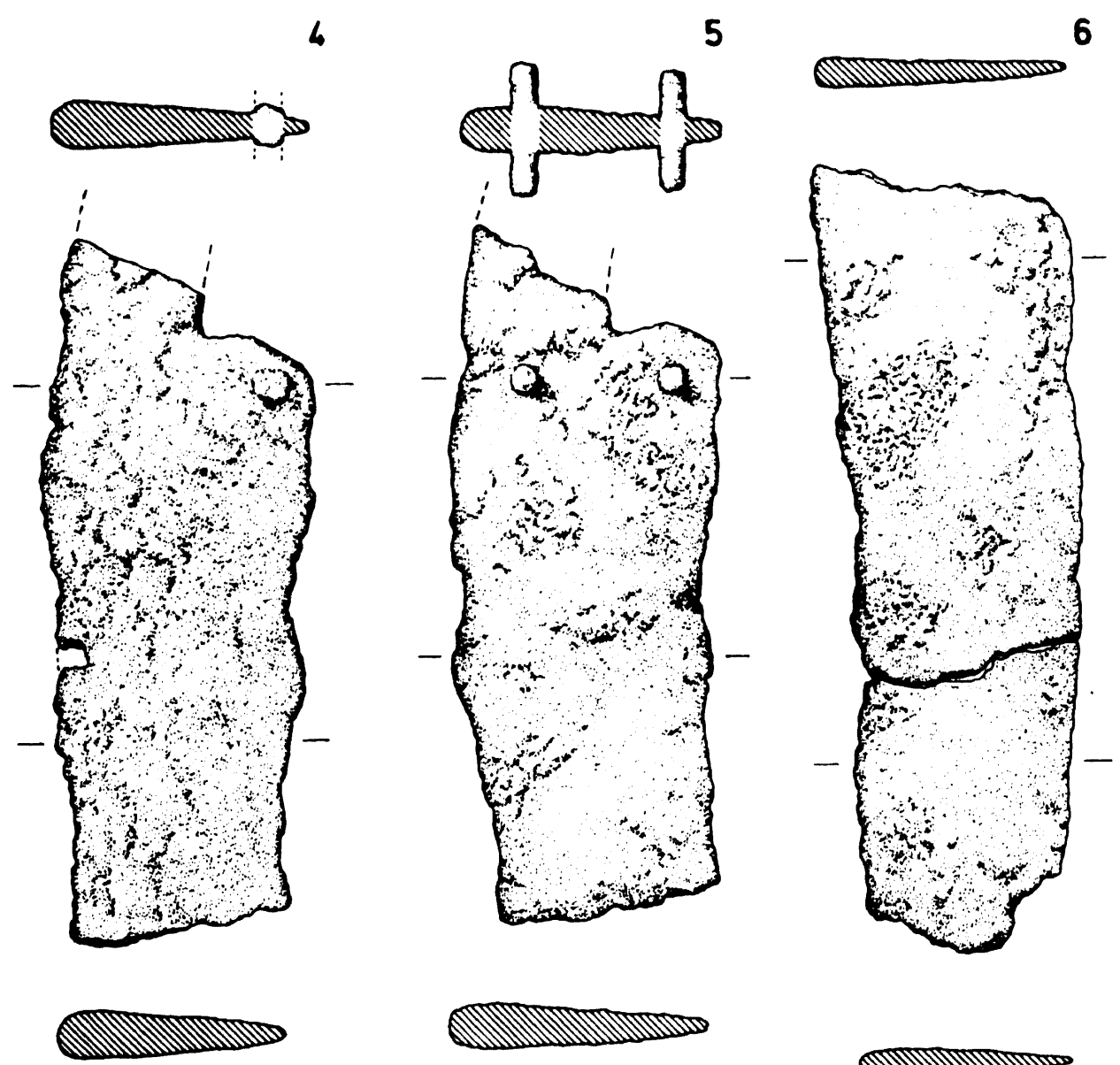

\section{6}
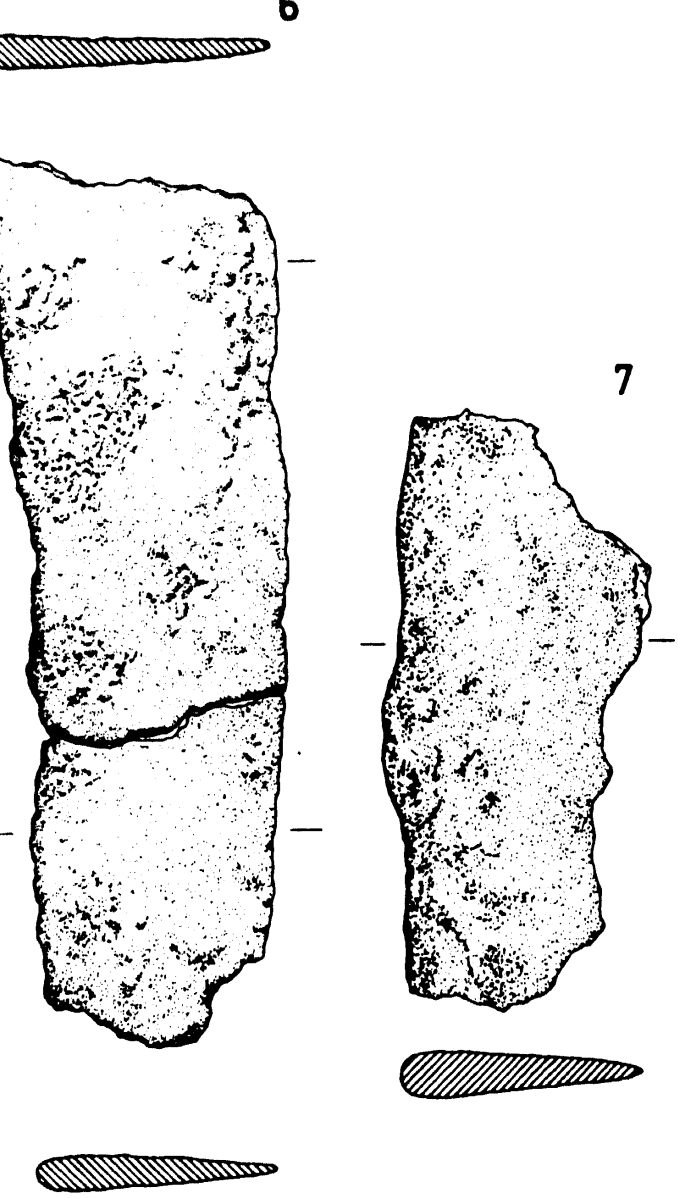

8
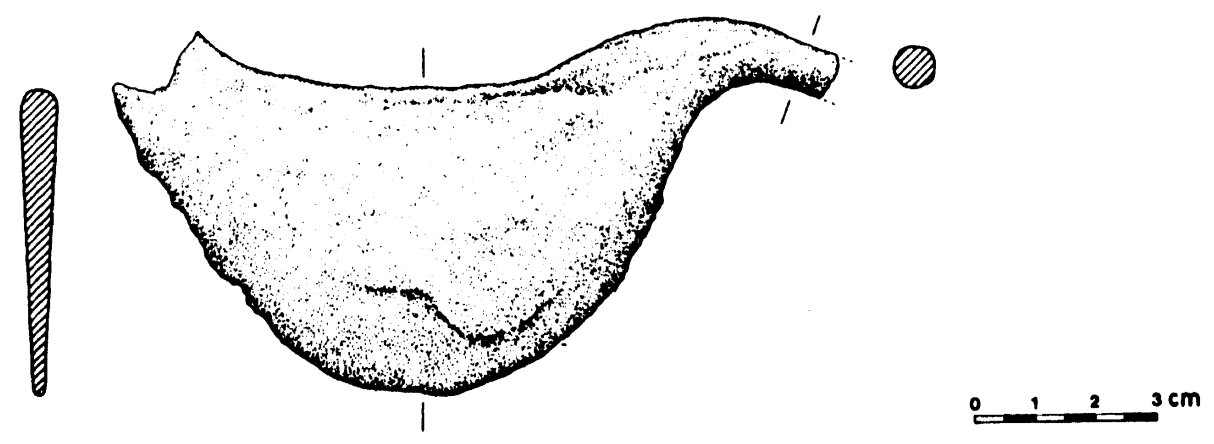

9

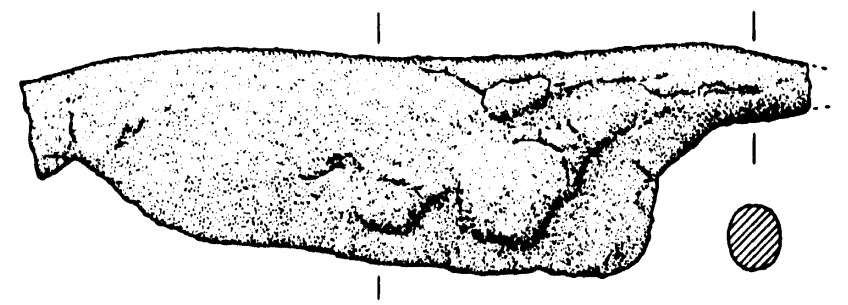

Fig. 4.-Espadas y cuchillos de hierro.

\section{T. P., 1991, n 48}

(c) Consejo Superior de Investigaciones Científicas Licencia Creative Commons 3.0 España (by-nc) 
Murada (Veny, 1983b: 394 y 396, fig. 6) y en Cales Coves han aparecido suficientes completos y fragmentos como para que C. Veny haya podido establecer una primera tipología con cuatro grupos: cuchillos de dorso recto, de dorso acodado, de hoja lunar con espiga en ángulo y microcuchillos (Veny, 1982: 351, lám. 197).

Respecto al pequeño cuchillo de Son Bauzá $\left(\mathrm{N}^{\circ} 8\right)$ con ancha hoja en forma de creciente lunar, no se conoce ningún otro objeto semejante que haya aparecido en la isla de Mallorca. Sin embargo, en Menorca, se han encontrado dos ejemplares parecidos en la cueva XIX y restos de otros cuatro en la cueva XLVIII de Cales Coves así como en Castellás de Forma, cuevas de Addaia y Sa Mola (Veny, 1982: 351). En opinión de C. Veny, este tipo de cuchillo de hoja lunar podría ser un modelo propio de las Baleares, ya que no existen paralelos claros fuera de las islas; pues los modelos continentales, que recuerdan por su forma un creciente lunar, se diferencian de los de Baleares por su largo mango, casi siempre acabado en una anilla y por la delgadez de la hoja.

La otra variedad de cuchillo documentada en Son Bauzá es el caracterizado por su hoja triangular de un solo filo y dorso más o menos recto, que se prolonga en una espiga para el enmangue ( $\mathbf{N}^{\circ}$ 9).

\section{Brazaletes (№ 10 a 29)}

La aparición de brazaletes de hierro es muy frecuente en los ajuares funerarios de época talayótica, tanto en Mallorca como en Menorca. Los hay de diversos tipos que se pueden agrupar de la siguiente manera (Veny, 1982: 353):

a) Aro simple, generalmente cerrado, con los extremos superpuestos o soldados.

b) Espirales, con un número de vueltas variable, desde tres hasta diecinueve. La sección del alambre suele ser circular y su grosor es máximo en el centro, disminuyendo progresivamente hasta los extremos. Pueden adoptar tres formas: tubular, troncocónica y bitroncocónica o de tonelete.

La denominación de brazaletes que damos a estos objetos se basa en que se han encontrado ejemplares in situ rodeando todavía huesos de extremidad superior humana (cúbito y radio). Su utilización como tobilleras parece también posible, pero no está atestiguada arqueológicamente. La variedad de diámetros de estos brazaletes parecen indicar su uso por individuos de distinta complexión y edad, pero faltan datos que confirmen o nieguen su utilización por ambos sexos.

Considerando el diámetro podemos establecer dos grandes grupos de estos objetos: uno, el de los brazaletes o tobilleras, con un diámetro interior que oscila entre 4 ó $5 \mathrm{~cm}$. como mínimo y que no supera los 9 ó $9,5 \mathrm{~cm}$. como máximo en ningún caso. Y un segundo grupo que probablemente nunca se usó en las extremidades por su reducido diámetro, inferior a $4 \mathrm{~cm}$. y que en ocasiones llega a tener tan sólo $1,2 \mathrm{~cm}$. y que han sido considerados como elementos de adorno y sujeción del cabello (Veny, 1982: 354 y Waldren, 1983: 424, fig. 139-140).

\section{Varillas (№ 30 a 36)}

En los yacimientos funerarios del último período talayótico es frecuente encontrar unas varillas de bronce caracterizadas por tener una chapita circular en cada extremo y una anilla $u$ orificio en el extremo superior para suspender - por medio de un alambre, cinta o cadena metálicas- un disco de bronce o, excepcionalmente de hierro.

Debido a los problemas lógicos de conservación y a la remoción de algunos yacimientos, no es lo más habitual encontrar in situ el conjunto formado por la varilla-soporte, el alambre y el disco, siendo lo más normal que se encuentren las piezas o sus fragmentos por separado. Sin embargo, 

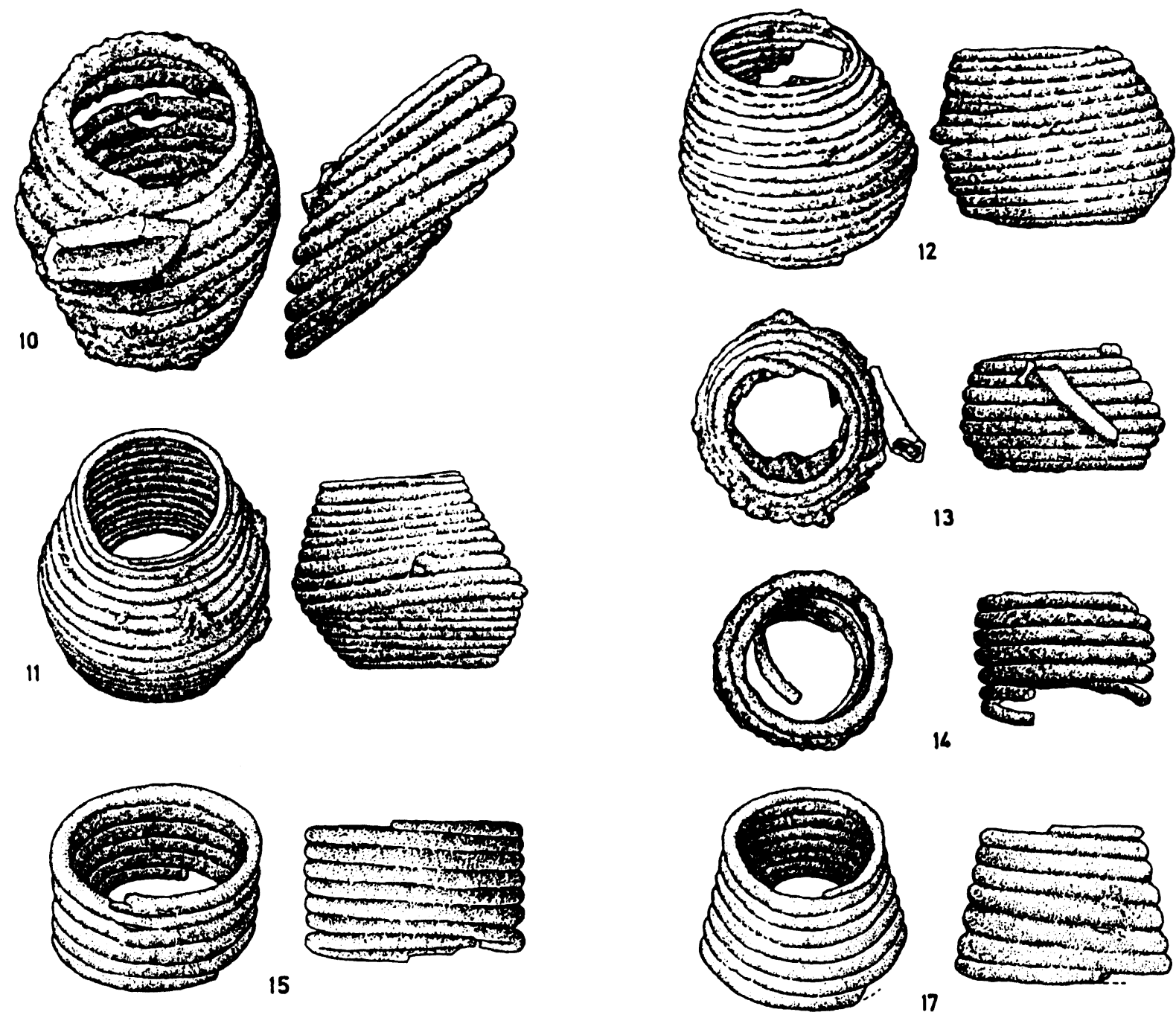

15
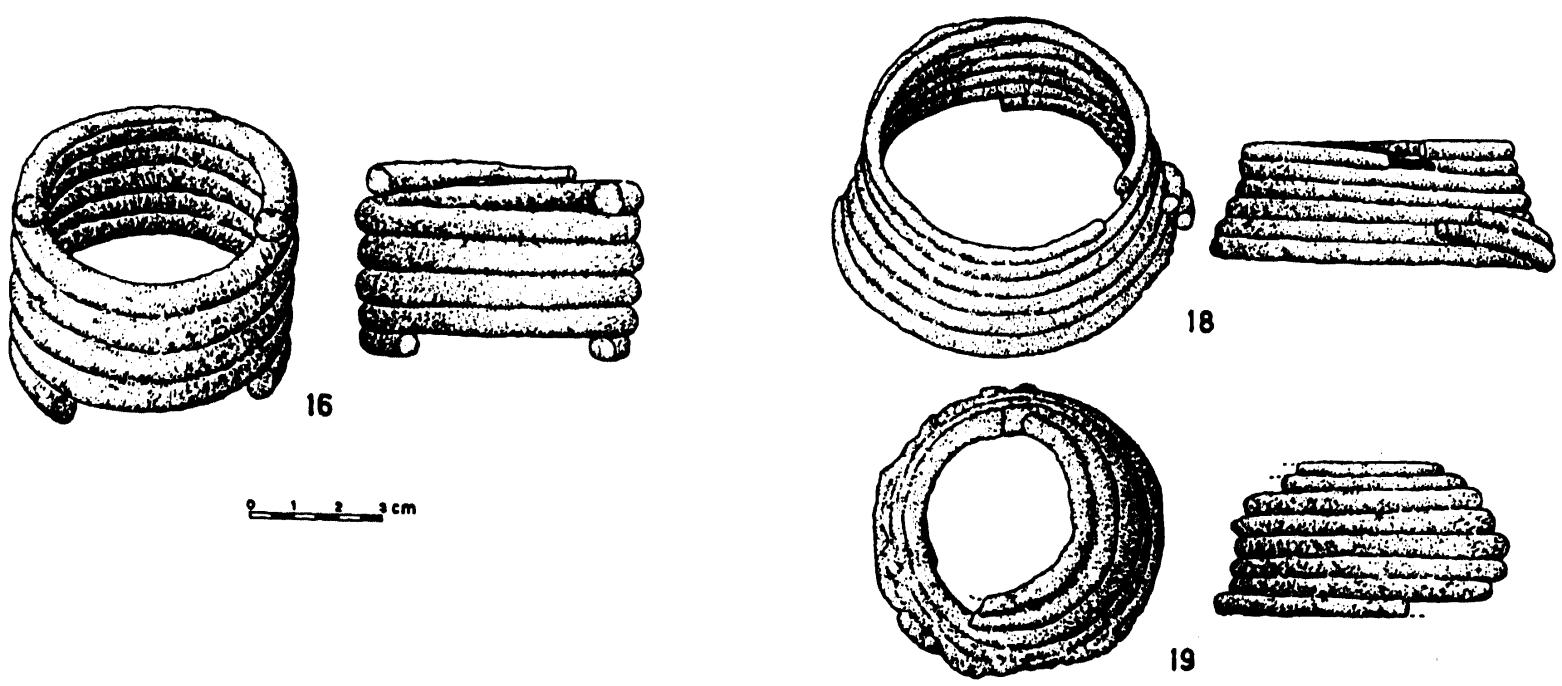

19

Fig. 5.-Brazaletes en espiral de hierro. Los números 10 y 13 conservan adheridos fragmentos de huesos humanos.

\section{T. P., 1991, n 48}



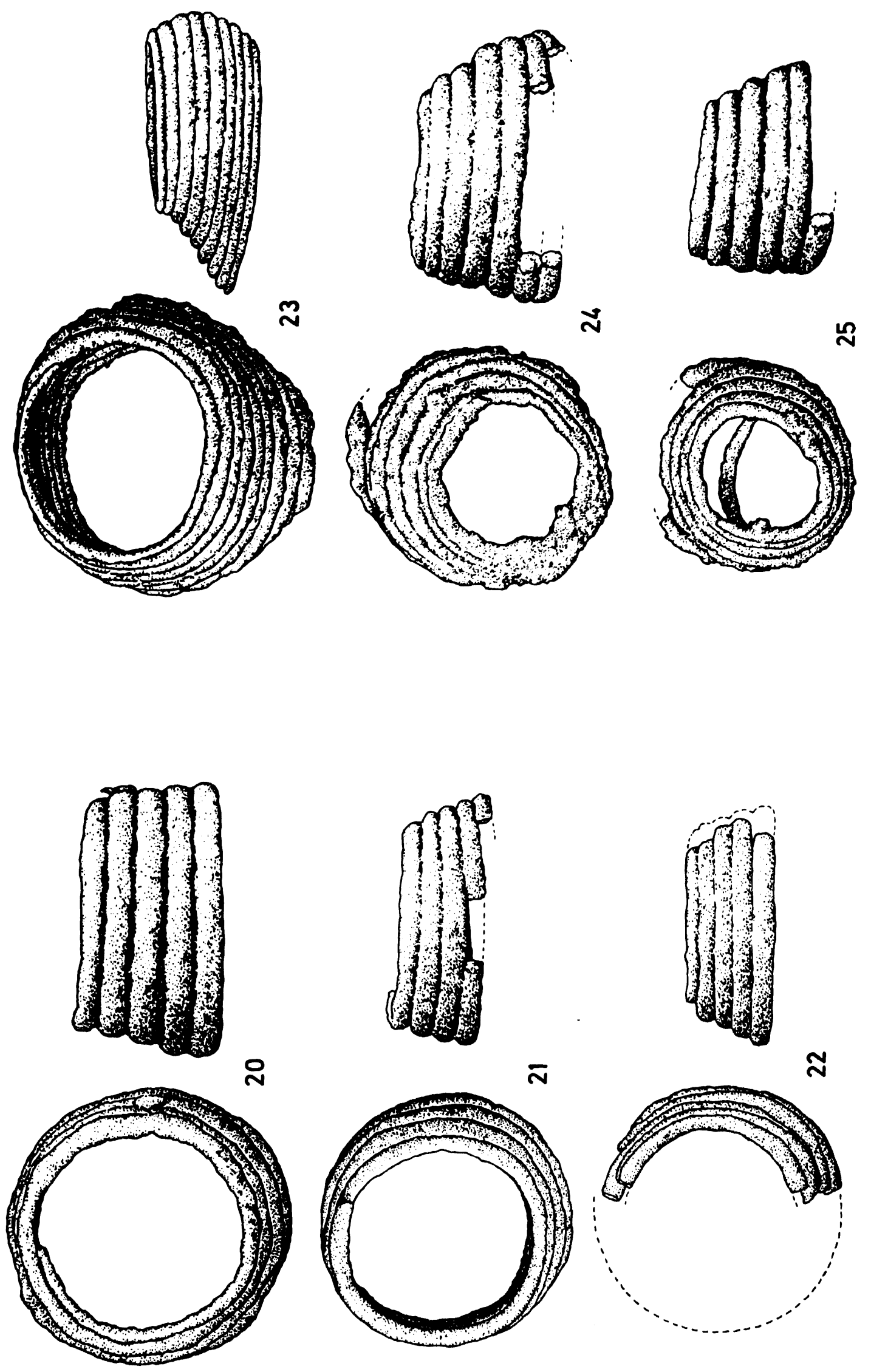

T. P., $1991, \mathrm{n}^{\mathrm{e}} 48$ 


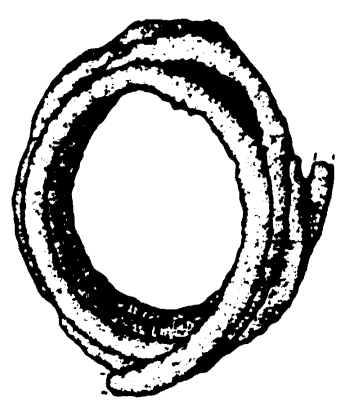

26

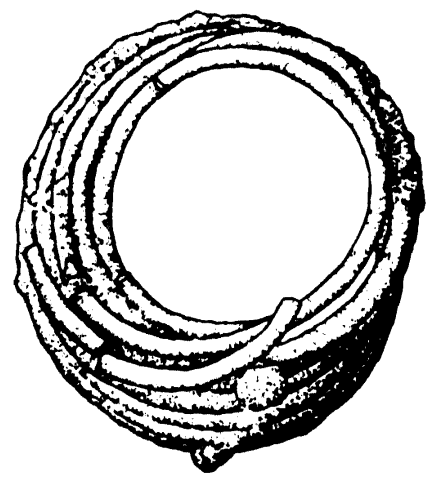

27
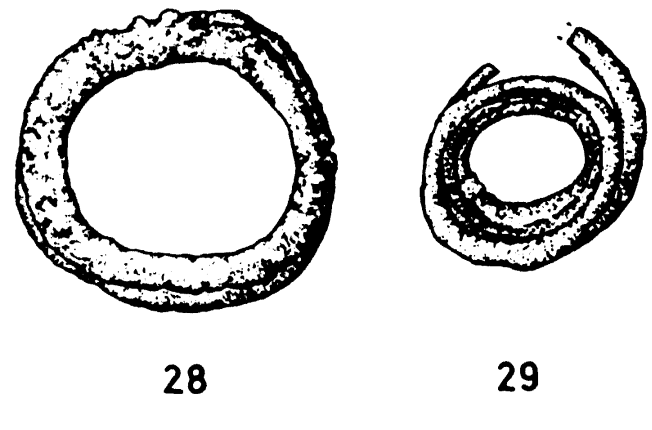

29

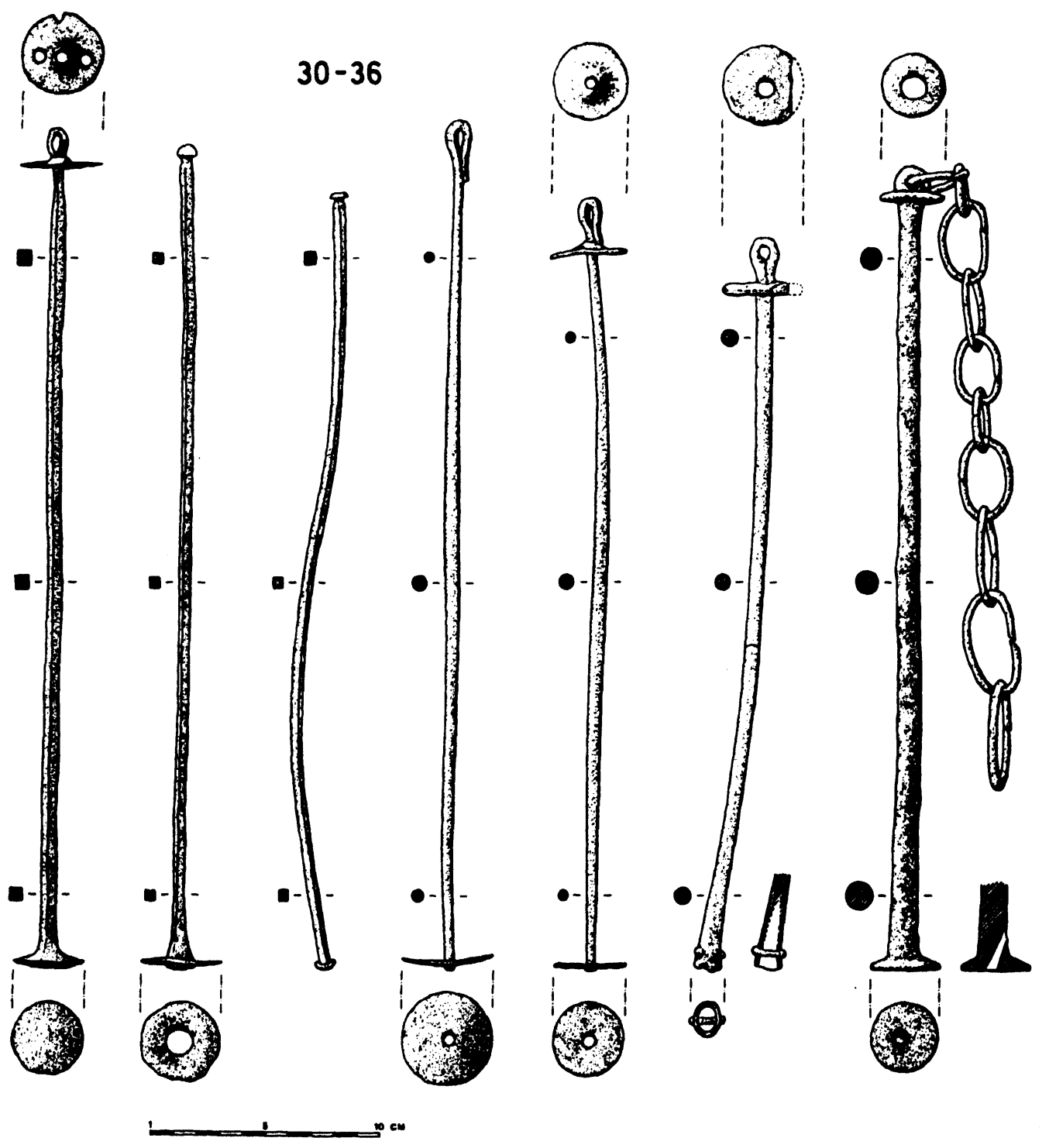

Fig. 7.-Números 26 a 29. Brazaletes en espiral de hierro. Números 30 a 36. Varillas-soporte de bronce para discos.

\section{T. P., $1991, \mathrm{n}^{9} 48$}

(c) Consejo Superior de Investigaciones Científicas

http://tp.revistas.csic.es 
son varios los ejemplares que se han hallado completos con sus tres elementos unidos entre sí. Esto permite asegurar la relación de las varillas con los discos de un determinado tipo (el tipo 2, que veremos más adelante). Los discos, por su robustez, se conservan mejor que los otros dos elementos (varilla y alambre), con lo que a veces se ha creido erróneamente que aparecian aislados sin relación con aquéllos. Se conocen actualmente los suficientes ejemplares completos como para considerar segura la existencia y uso de este objeto exclusivo y característico de Mallorca, cuya denominación parece compleja; como la interpretación de su función o significado dentro del ajuar funerario y el rito de enterramiento.

Posiblemente sea aventurado querer establecer una tipología de estas varillas, tanto por la escasez de los ejemplares publicados como por el estado fragmentario de muchos de ellos. A esto hay que añadir que son contados los ejemplares completos que conservan el alambre, cinta o cadena y el disco suspendido. Por esto, de momento, la clasificación tipológica ha de hacerse separando por un lado las varillas y por otro los discos; mientras que de los alambres, cintas y cadenas de suspensión apenas se puede decir otra cosa que constatar su existencia.

Volviendo a las varillas, se documentan dos tipos de sección: cuadrangular o rectangular y redondeada. El extremo superior puede terminar de tres formas: con anilla formada por el pliegue del extremo de la varilla; con anilla formada por la perforación del extremo, previamente aplastado y, por último, remachado simplemente. El extremo inferior, también, puede acabar de tres formas: con remate macizo en forma lenticular, con una chapita discoidal remachada o con el extremo de la varilla hueco, con un pasador. Algunos ejemplares con remate macizo en forma lenticular llevan un orificio en el extremo inferior, en dirección oblícua, que entra por un lado de la varilla y sale por el centro de la base; pudiera haber servido para introducir un clavo que sujetase la varilla en determinada posición.

Las dimensiones de las varillas conocidas oscilan entre los 28 y $44 \mathrm{~cm}$. de longitud y su grosor entre 4 y 7,5 mm., llegando hasta $14 \mathrm{~mm}$. en los casos más robustos.

\section{$\operatorname{Discos}\left(\mathrm{N}^{\circ} 37\right.$ a 49$)$}

Una de las series de objetos más curiosos del final de la cultura talayótica es la constituida por discos de bronce o cobre de diverso tamaño y tipología, que aparecen exclusivamente en ambientes funerarios y cuyo uso concreto no ha sido posible determinar por el momento.

Se ha propuesto para estos discos una tipología basada en su decoración y tamaño (FernándezMiranda, 1978: 275), distinguiendo tres tipos:

Tipo 1. Los de mayor tamaño, de placa muy delgada y repujada, con marcado umbo central; pueden estar decorados o no.

Tipo 2. Discos de menor tamaño que los anteriores, pero de mayor grosor, llevan un pezón central en el anverso y a veces decoración en relieve o grabada; en el reverso tienen un asa.

Tipo 3. Más pequeños aún, con el anverso decorado a base de círculos concéntricos en grupos.

Tomando esta clasificación como base, ampliamos el comentario sobre los dos primeros tipos, que son los únicos documentados en Son Bauzá.

Los discos del tipo 1 son de lámina de cobre o bronce muy delgada, a veces llevan decoración repujada con motivos de carácter geométrico (líneas, zig-zags, aspas, puntos, umbos, etc.) o vegetal esquemático (rosetas, hojas de vid, racimos de uvas, hojas de hiedra, etc.), dispuestos en círculos concéntricos alrededor de un umbo central muy pronunciado. Algunos de estos discos presentan un gran abombamiento, a modo de plato sopero, que ha hecho que sean confundidos con páteras (Enseñat Enseñat, 1981: 109). El uso de estos discos no está claro, pero todo parece indicar que su 

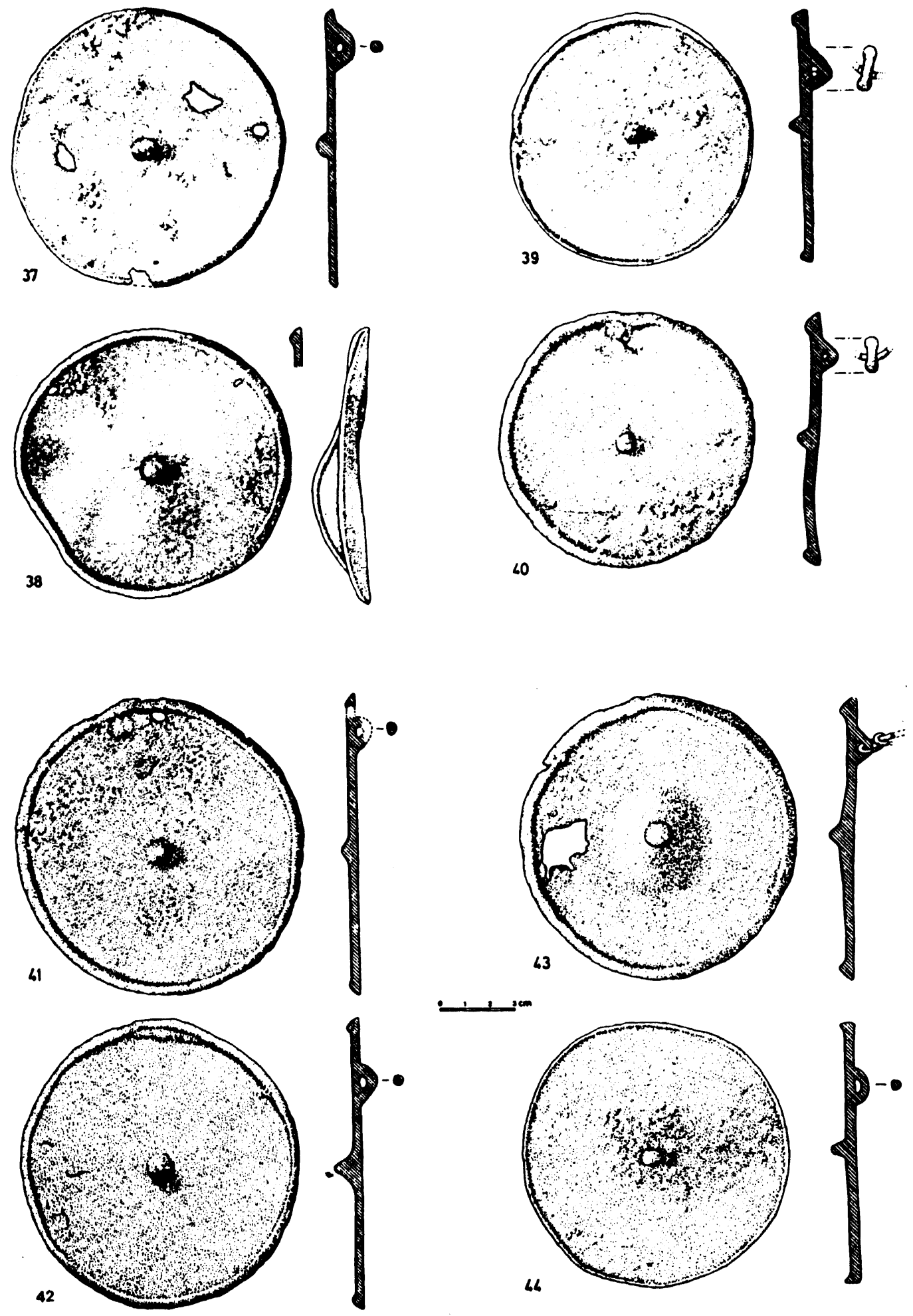

Fig. 8.-Discos de bronce.

T. P., 1991, ne 48

(c) Consejo Superior de Investigaciones Científicas Licencia Creative Commons 3.0 España (by-nc) 

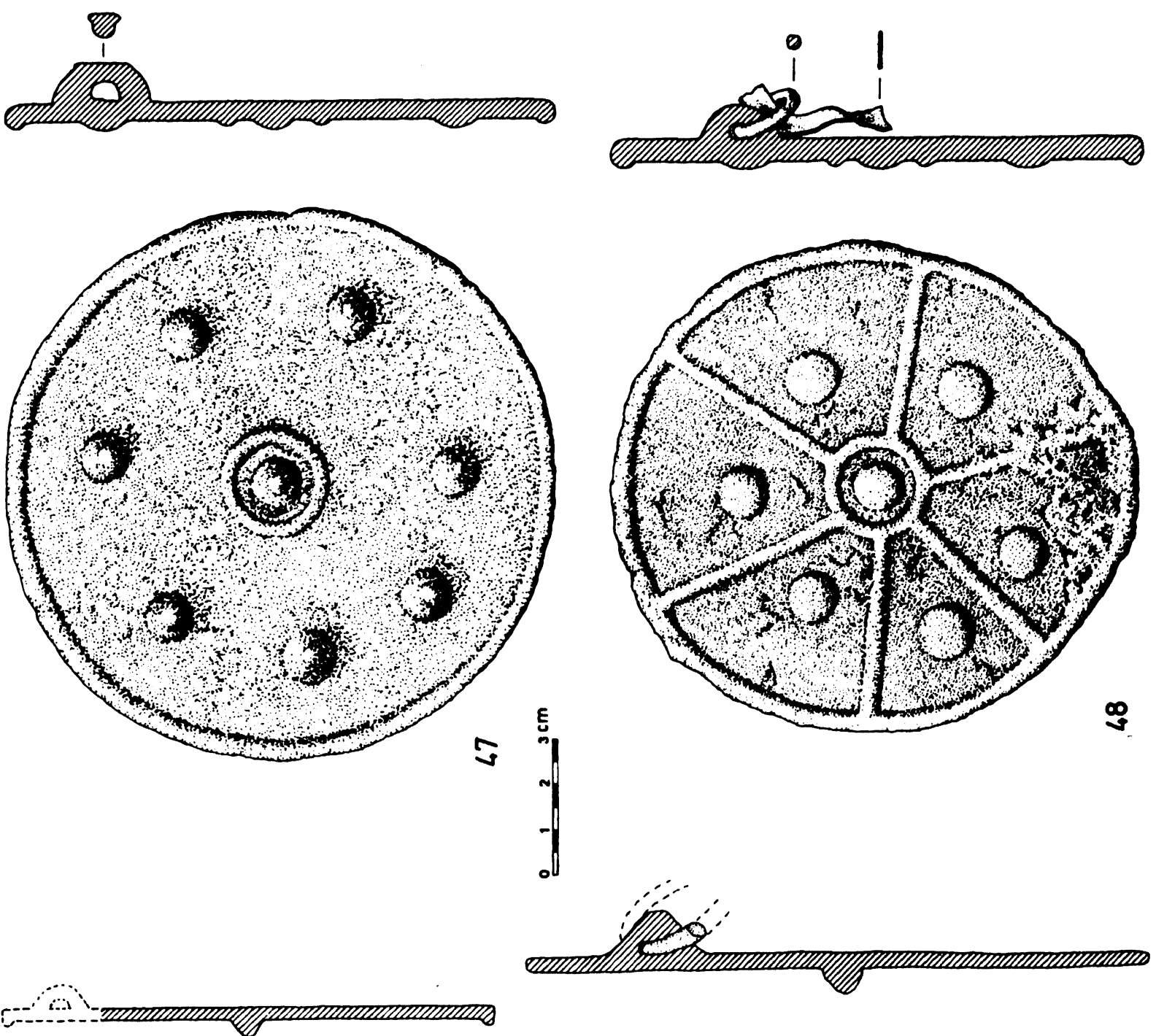

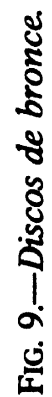

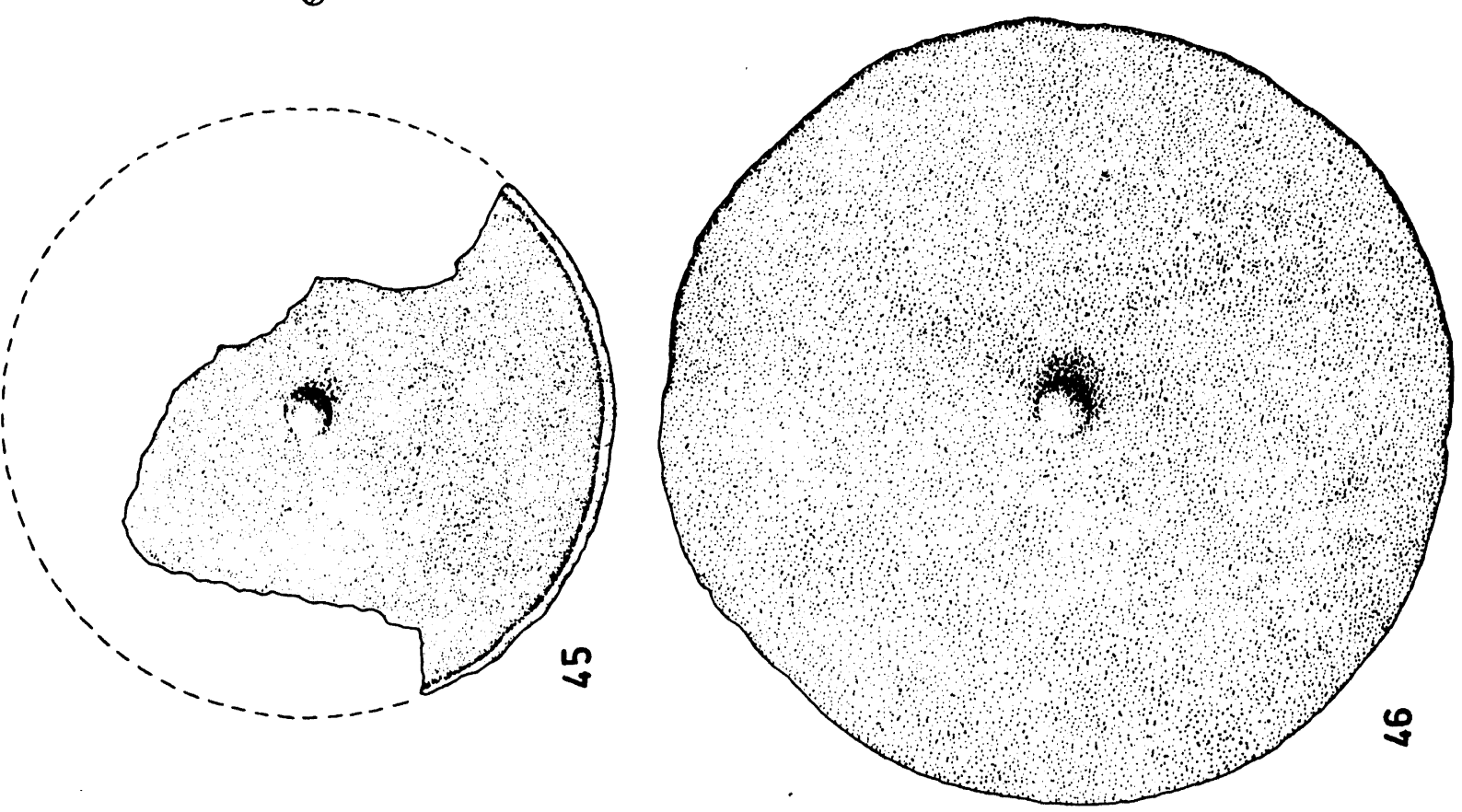

T. $P ., 1991, \mathrm{n}^{2} 48$ 
utilización se hacian en sentido vertical, a modo de gong, pudiendo estar suspendido el disco de dos formas diferentes:

a) Con un mango formado por una delgada cinta recta que está soldada o remachada al borde del disco y termina en una voluta que en un ejemplar de la Cometa dels Morts recuerda la cabeza estilizada de un cisne (Veny, 1947: fig. 27). Hacia la mitad del mango, aproximadamente, cuelga un alambre o cadenita que termina en un abultamiento que hace de badajo o percutor al golpear sobre la superficie del disco.

b) El otro sistema de suspensión consiste en un alambre con un lazo en cada extremo. Este, partiendo del borde del disco, se une a otra anilla de la que a su vez cuelga otro alambre, rematado en su extremo inferior por un abultamiento que hace las veces de badajo, como en el caso anterior.

El diámetro de los discos del tipo 1 oscila entre los 12,5 y los $35 \mathrm{~cm}$. y el grosor de la lámina de que están hechos varía entre 1 y $2 \mathrm{~mm}$.

Los discos del tipo 2 son, con mucho, los más abundante. Están fundidos y se caracterizan por tener un acusado pezón central, $\mathbf{y}$, con frecuencia, una moldura en relieve en el borde del anverso. En el reverso tienen un asa o, en su defecto, un pequeño orificio que sirve para suspenderlos - por medio de un alambre, cinta o cadena-, de una varilla de bronce que hace las veces de soporte. En el anverso suelen llevar decoración en relieve (molduras concéntricas, hemiesferas, radios) o grabada (círculos concéntricos de pequeño tamaño, en grupos de dos, trazados a compás). El tamaño de estos discos oscila entre 7 y $13,5 \mathrm{~cm}$. de diámetro y el grosor de la plancha oscila entre 2 y $4 \mathrm{~mm}$.

Este tipo de discos ha sido denominado tintinabulla en repetidas ocasiones (Rosselló-Bordoy y Waldren, 1973: 26; Roselló-Bordoy, 1974: 124; Veny, 1982: 306), pero creemos que tal denominación corresponde mejor a una verdadera campanilla o cascabel más que a un disco o gong (DarembergSaglio, 1969: 341-344).

Se ha querido encontrar paralelos para los discos del tipo 1 fuera de las islas, sobre todo en la meseta ibérica, en Italia y en Francia (8), prestando atención sobre todo a las semejanzas en la decoración. Así, basta con consultar repertorios clásicos como los de Montelius o los más recientes de Müller-Karpe o Schüle (Montelius, 1895; Müller-Karpe, 1966; Schüle, 1969: láms. 3 y 5) para encontrar, repartidas por toda Europa, numerosas láminas metálicas de forma circular y variadas dimensiones, con decoración repujada o incisa cuyos motivos son los botones, pequeños umbos, ángulos y líneas en relieve que forman círculos concéntricos y estrellas con numerosas puntas, todo ello con una marcada orientación geométrica. Pero además de los parecidos formales, hay que considerar varios argumentos en contra de estos posibles paralelos europeos:

a) Estos discos nunca aparecen con los mismos elementos (badajo y alambre de suspensión) que los mallorquines y en la mayoría de los casos es seguro que nunca los tuvieron; con lo que, aún admitiendo su empleo para fines similares, por lo menos su utilización era diferente.

b) La mayoría son de menor tamaño que los de Mallorca, pues suelen ser adornos para sujetar sobre otros materiales, cuando no son colgantes, placas de correaje o partes de una fíbula. Los de mayor tamaño y más parecido con los de Mallorca son en algunos casos atalajes ceremoniales para llevar sobre la ropa (Schüle, 1969: lám. 3 y 5) y en otros, laterales de cantimploras metálicas parecidas a lo que en cerámica sigillata será la forma Hermet 13.

c) El gran parecido de algunas decoraciones tampoco indica más que todos estos objetos están en la órbita de las influencias célticas de las culturas europeas de la Edad del Hierro, que heredan

(8) Fernández-Miranda (1978: 277-279), ve paralelos en cuanto a la decoración entre las culturas de los terramara, en el mundo de las sítulas y en la Cumas prehelénica. En la Meseta encuentra paralelismos en Aguilar de Anguita y Alpanseque. Por su parte, Enseñat Enseñat (1981: 111), cita también varios paralelos italianos y uno francés. 
la simbología decorativa del disco solar y de la rueda, conocidos y difundidos desde la Edad de Bronce (Dechelette, 1913: 458, fig. 190).

Encontrar paralelos para los discos del tipo 2 (discos suspendidos de una varilla) fuera de las islas también resulta problemático. La decoración en relieve de alguno de estos discos (radios, botones hemiesféricos, molduras en círculos concéntricos, etc.), está evidentemente emparentada con el repertorio decorativo del disco solar y de la rueda, como señalábamos anteriormente. Se los ha relacionado con piezas ibicencas parecidas a címbalos (Enseñat Enseñat, 1981: 111).

Entra dentro de lo posible que fueran usados como instrumento musical, bien al golpear el disco contra la varilla soporte o percutiendo sobre él con una varita de material duro. Ahora bien, lo mismo podían ser elementos de adorno o tener carácter emblemático o simbólico, o todo a la vez, ya que no hay datos seguros que avalen esta explicación o cualquier otra. Lo que sí está fuera de toda duda es que aparecen únicamente en las necrópolis, formando parte del ajuar funerario. También es bastante probable que sólo se depositara uno de estos objetos en cada enterramiento, cuando se hacía.

Se ha escrito que en la cueva de Son Ribot apareció un disco liso colocado sobre la boca de uno de los esqueletos y la varilla junto al brazo. Asimismo, en Son Bosc se halló un disco liso de poco espesor colocado en la zona correspondiente al pecho (Enseñat Enseñat, 1981: 110 y ss.). Por desgracia, estas dos observaciones son únicas entre la bibliografía sobre el particular, ya que no existen referencias acerca de la disposición de estas piezas en los enterramientos en ningún otro yacimiento. Con estos datos resulta problemática la interpretación de estos objetos; aunque B. Font Obrador, basándose en su excavación de Son Ribot, de por sentado que "los discos circulares se colocaban sobre la boca del difunto, la varilla quedaba sujeta en sus manos. Quizá correspondería a los atributos de poder de los inhumados, jefe, chamán, etc." (Font Obrador, 1970: 381). Más extendida es la denominación de tintinabulla para tales objetos, aceptando con ello una utilización musical de los mismos (Rosselló-Bordoy y Waldren, 1973: 26).

\section{Puntas de lanza (№ 50 a 53)}

Tanto en Mallorca como en Menorca son numerosos los hallazgos de puntas de lanza u otra arma arrojadiza similar realizadas en bronce siguiendo distintos modelos, pero siempre con enmangue tubular cónico que se prolonga hasta la punta y dos aletas simétricas. Tipológicamente las hay que responden a modelos mediterráneos y centroeuropeos; y menos que responden a tipos atlánticos (Veny, 1977: 123). Para algunos tipos de puntas baleares se han propuesto cronologías del siglo X y IX a. de C. (Bosch Gimpera, 1954: 31; Roselló-Bordoy y Waldren, 1973: 26; Veny, 1982: 306), pero la mayoría se engloban dentro del Bronce Final. Entre el siglo VIII y VI a. de C. las sitúan muchos autores, señalando también que con frecuencia aparecen en contextos en los que se encuentra ya el hierro (Enseñat Enseñat: 1981: 148; Veny, 1977: 120-123 y 153; Veny, 1982: 306 y ss). Los tipos más modernos de estas puntas entre las que no dudamos en incluir las cuatro de Son Bauzá, pueden ser. perduraciones con cronologías avanzadas, siendo posible que lleguen hasta tiempos inmediatos a la romanización (Fernández-Miranda, 1978: 274-275).

\section{Campanillas (№ 54 a 60)}

Su presencia es casi obligada en las necrópolis de Mallorca y Menorca, contabilizándose cerca de un centenar. Irían colgadas de collares - de alambre de hierro, en ocasiones-, con cuentas de pasta vítrea. Lo prueban un collar completo de Son Cresta y las campanillas con fragmentos de collar de Son Maimó, Son Bosc y Cova Monja; y así debió aparecer alguna en Son Bauzá, según lo cuenta el P. Lliteras (1929).

Todas llevan en la parte superior una abertura para colgarlas, de distintas formas y tamaños. 

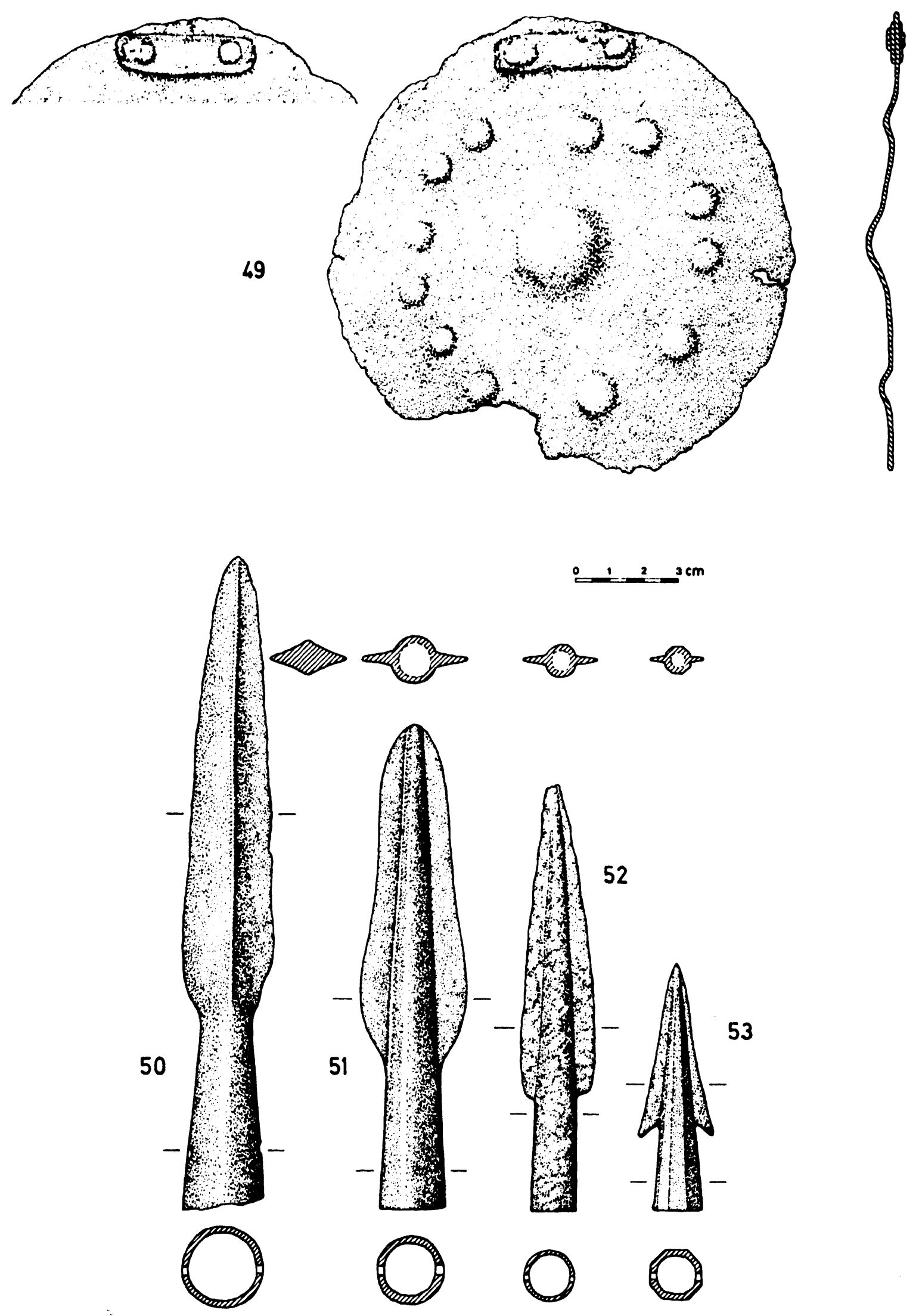

Fig. 10.-Número 49, Disco de bronce. Números 50 a 53, Puntas de bronce. 


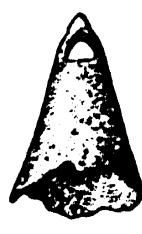

54

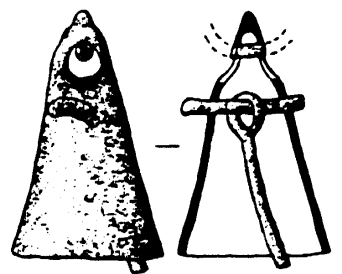

57

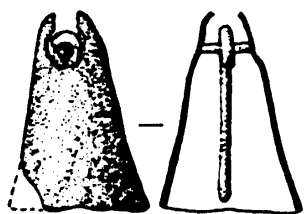

59

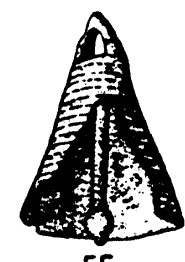

55

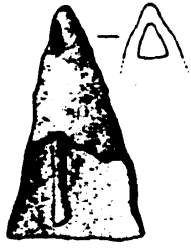

56

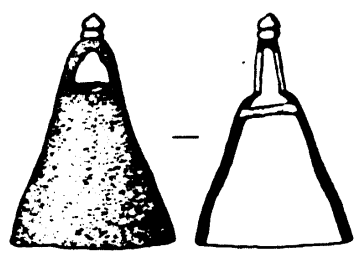

58

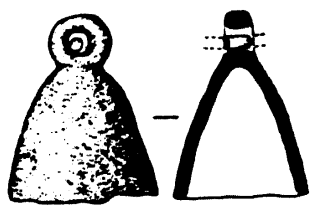

60

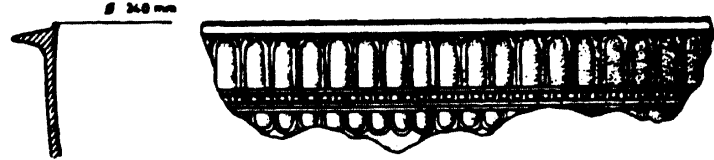

61

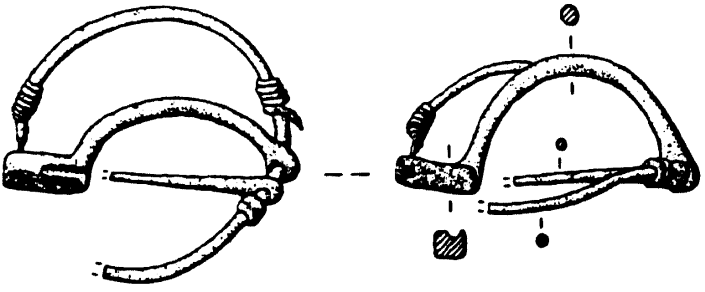

62

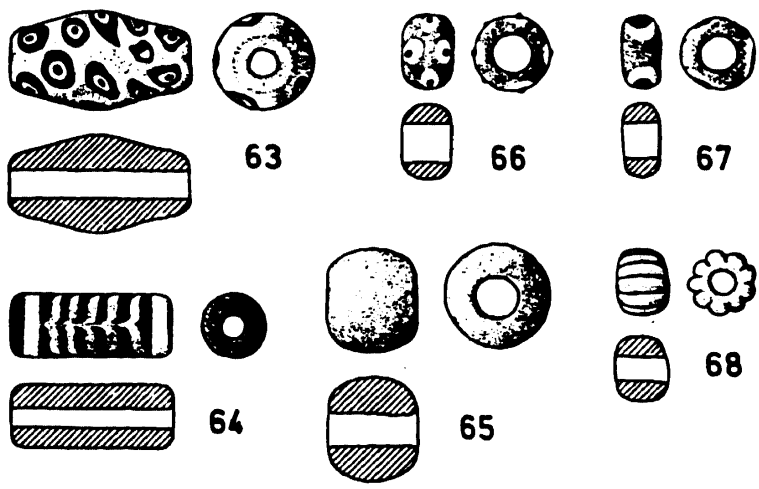

(2)
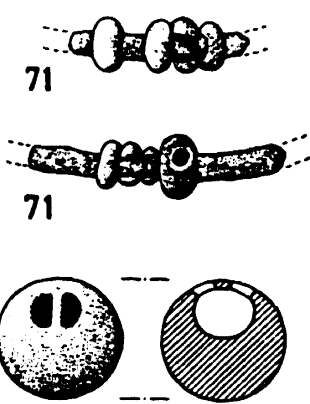

72

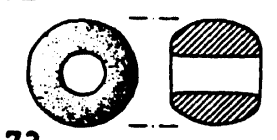

73
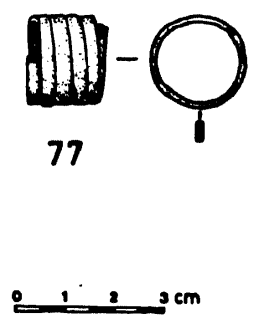
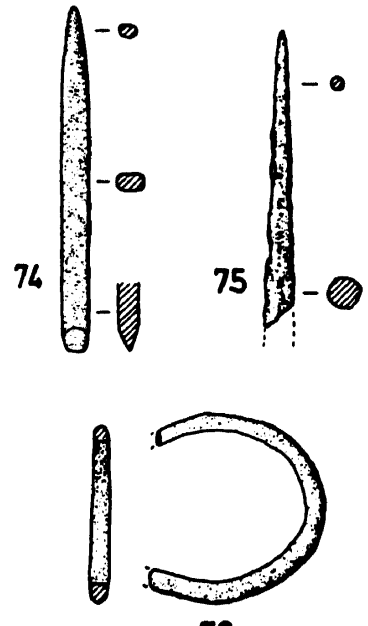

76

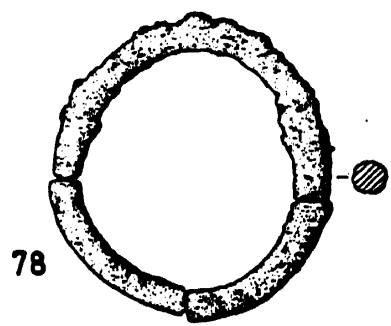

FIG. 11.-Nümeros 54 a 60. Campanillas de bronce. Número 61. Fragmento de borde de recipiente de bronce. Número 62. Fíbula anular de bronce. Nümero 63 a 69. Cuentas de pasta vítrea; en el recuadro, desarrollo de motivos acumulados de estas cuentas. Número 71 a 78 . Materiales varios. 
Son de bronce o cobre, salvo dos ejemplares de Cova Monja y Son Taixaquet, al parecer de hierro. Todas llevan badajo suspendido de un pasador o de una cinta metálica. Tanto el badajo como el travesaño pueden ser de bronce o de hierro. Muchas llevan decoración en la parte exterior, con líneas incisas paralelas formando bandas o cubriendo completamente la pared.

El tamaño de los ejemplares documentados oscila entre los 2 y $7,8 \mathrm{~cm}$. de altura y un diámetro de la boca de 1,6 a $6,3 \mathrm{~cm}$.

En Ibiza, en la necrópolis púnica del Puig dels Molins, se han hallado numerosas campanillas similares en todo a las de Mallorca y Menorca. Algunas incluso forman parte de collares con cuentas de pasta vítrea y otros adornos, asociados a terracotas de la diosa Tanit. En la Península también son frecuentes estas campanillas en zonas próximas o bien comunicadas con el litoral mediterráneo.

La cronología de estas campanillas es muy imprecisa, como lo es la de la mayoría de los materiales con que parecen asociadas en las Baleares. C. Veny, basándose en una campanilla de la incineración № 9 de Las Corts y en otra de la inhumación № 5 de la necrópolis Bonjoan, ambas en Ampurias, establece los extremos cronológicos en que el uso de estos objetos tuvo plena vigencia: siglo IV a I. a. de C.

Por otra parte, se acepta generalmente que estas campanillas son de factura y origen púnicos (Cintas, 1976: lám. LXXX) y que se difunden como una más de las baratijas aportadas por aquellos en su comercio con otros pueblos mediterráneos. Si tenemos en cuenta la fecha de la fundación de la colonia púnica de Ibusim, que según la tradición conservada por Diodoro es el año 654 a. de C. y que los restos arqueológicos más antiguos conocidos de la colonia no parecen remontarse tan atrás en el tiempo, tendríamos que considerar que estas campanillas no empezaron a difundirse masivamente en Baleares, por lo menos, hasta el siglo VI a. de C. Su pervivencia quedará limitada por la romanización de las Baleares, cuyo inicio se presume en el año 123 a. de C., con la conquista dirigida por Quinto Cecilio Metelo Balearico.

Fernández-Miranda, aunque admite como probable el origen ebusitano de las campanillas, considera que también pudieron ser importadas en Mallorca ya en pleno contacto con la romanización, dado que el uso funerario de algunas cuevas del tipo de la de Son Bauzá en fechas posteriores al 123 a. de C. está de sobra probado (Fernández-Miranda, 1978: 280 y ss).

\section{Recipiente de bronce (№ 61)}

En Mallorca son raros los hallazgos de recipientes de bronce procedentes de yacimientos prerromanos. Se conocen algunos restos de Son Taixaquet, Son Favar, Cometa dels Morts, Costix y Sa Roca Rotja (9). Estos restos son muy diferentes entre sí, pues responden a elementos distintos: jarro, fuente, pátera, asa, etc.; pero han sido considerados en conjunto como piezas importadas, quizás de procedencia itálica, prerromanas y romanas (Fernández-Miranda, 1978: 282).

El pequeño fragmento de Son Bauzá apenas deja adivinir el tamaño y forma aproximada del recipiente al que pertenecía. Su muy cuidada decoración, que nos indica que se trataba de una pieza de calidad, sitúa este recipiente en la línea de una tradición decorativa y de trabajo del bronce griegas, que se remonta al menos hasta mediados del siglo VI a. de C. El mismo tipo de decoración realizada con una técnica mixta de molde y retoque de cincel o punzón, cuyos motivos son gallones, lengüetas u ovas alargadas en sutil relieve, lo encontramos en una obra tan caracterizada como la Crátera de Vix. También son frecuentes estos motivos sobre otros recipientes griegos y etruscos, además de espejos, cascos, pedestales de figurillas, etc. con una cronología que abarca los siglos VI

(9) Para los yacimientos citados: Bosch-Gimpera y Colominas (1937: planche XVI (3)); Amorós y Garcia y Bellido (1947: 10-11, fig. 11, 15, 16); Veny (1947: 55, fig. 18 y 1950: 325); Fernández-Miranda (1978: 282-283). 
y V a. de C. (10). Es sabido, por otra parte, que esta técnica y motivos decorativos perduran también durante los siglos siguientes IV y III a. de C.

Que el fragmento de Son Bauzá perteneciera a una obra de tanta antigüedad como las mencionadas entra dentro de lo posible, pero también lo es que pudiera tratarse de una obra posterior, imitación romana o de época romana siguiendo pautas decorativas de la tradición griega y grecoetrusca.

\section{Fíbula anular (№ 62)}

Estudiada por E. Cuadrado, la clasificó como "fíbula de aguja libre con tope de charnelo», datándola en la segunda mitad del siglo V. a. de C. (Cuadrado, 1963: 57-58, fig. 13, f); precisando que «el tope de charmela está roto, pero quedan restos del mismon. Tanto en el dibujo que publicó en su día como en el que presentamos ahora no se aprecia el referido tope de charnela o "chapita en $U_{\text {" }}$ que caracterizaría este tipo. Por lo tanto, el sistema usado para hacer resistencia a la aguja podría ser de dos tipos: el referido tope de charnela con chapita en $\mathrm{U}$ o bien, por la unión de las espirales de alambre de las que quedan restos a ambos lados de la cabeza del puente y de la aguja, sobre el anillo; y que serviría a la vez para evitar el desplazamiento lateral de estas piezas y para hacer de tope y resorte a la aguja.

Esta fíbula no tiene paralelos conocidos en Baleares. En la Península, E. Cuadrado cita tres ejemplares parangonables al de Son Bauzá: fíbulas de Amposta (fines del VI o principios del V a. de C.), Esplugas de Francolí (525-425 a. de C.) y Alcalá de Chisvert (siglo VI a. de C.). La fíbula de Son Bauzá presenta ciertas diferencias respecto de las citadas, como su notable robustez y su puente de sección redondeada, probablemente fundido. Ante la falta de otros datos, tomaremos como base la fecha propuesta por E. Cuadrado y apuntamos la doble posibilidad de que sea una pieza importada de la Península, como parecen serlo otros tipos de fíbulas hallados en Mallorca; o que sea una imitacion local, ya que tampoco faltan los ejemplos de creación de modelos de fíbulas, en la isla.

\section{Cuentas de pasta (№ 63 a 71)}

Añadimos a lo dicho sobre los collares anteriormente, que de la cueva de Son Bauzá se conservan 120 cuentas de pasta vítrea engarzadas modernamente en dos collares, con 64 y 65 cuentas, que llevan los números de inventario del Museo de Mallorca 8966 y 8967 respectivamente. No hay dos iguales, cosa lógica en un producto artesanal; sin embargo, se pueden agrupar en tipos bien definidos: una cuenta en forma de huso con óculos (№ 63), una cilíndrica con motivo vegetal (№ 64), una cuenta esférica de casquetes truncados, sin decorar ( $\mathrm{N}^{0}$ 65), cuentas globulares achatadas decoradas con óculos (№s 66 y 67), siete cuentas gallonadas ( $N^{2} 68$ ), cuentas globulares achatadas sin decorar ( $\mathrm{N}^{2}$ 69). Los colores utilizados son: blanco, amarillo, verde claro, azul y negro.

Todos los autores consultados convienen en afirmar que estas cuentas son uno más de los productos del comercio púnico. Su lugar de fabricación pudo estar en Ibiza, aunque no se descarta la procedencia directa de Cartago o Egipto. Se apunta incluso que algunas de estas se hubieran fabricado en Mallorca (Veny, 1981: 270).

En cuanto a la interpretación de la presencia de estas cuentas y collares en ajuares funerarios, se ha señalado la frecuencia con que en Ibiza se adornaban las terracotas de la diosa Tanit con elementos de este tipo. El gusto de los púnicos por los motivos oculados con que se decoran muchas de estas cuentas y su asociación con las campanillas de bronce -además de otra gran variedad de colgantes- sobre imágenes de la diosa cartaginesa por excelencia debía tener una

(10) Véase Richter (1980: fig. 269, 300, 302-304, 306 y 308); Pallotino (1956: fig. 50-51, 58 y 73); Hus (1975: fig. 28 y 39); Blázquez (1960: 197 y ss.). 
motivación que trascendía probablemente el mero capricho estético. Que esto fuera asimilado por otros pueblos, en este caso los baleares, que adquirian o trocaban estas cuentas es ya una suposición. Ahora bien, en las necrópolis de Mallorca y Menorca se han encontrado collares o agrupaciones de cuentas que presuponen la existencia de collares completos que se enterrarian con el difunto como parte de su indumentaria más o menos habitual (no hay datos sobre el sexo del difunto y la presencia o no de cuentas). Pero también se ha señalado que a veces aparecen apenas unas pocas cuentas esparcidas sin conexión aparente y en número tan escaso que hacen pensar que habían sido dispuestas al azar sobre los restos del difunto en el momento del enterramiento (Veny, 1982: 366). La interpretación de este hecho puede ser sugerente, pero por ahora es aventurado sostener que con estos avalorios los baleares adquirían de los púnicos algo más que un elemento suntuario que debía ser extraordinariamente grato para su sentido estético.

Problemática es también la datación de estas cuentas. Por sí solas sólo indican que hay que englobarlas en la esfera del comercio púnico. Están presentes en toda la cuenca mediterránea desde el siglo VI hasta el II a. de C. y tuvieron una gran difusión. Si consideramos las cuentas que aparecen en las Baleares como productos ibicencos, la fecha del año 654 a. de C. -según la tradición literaria-, marcaria el término post quem; que quedaria matizado si tenemos en cuenta que casi la totalidad de los objetos del Puig dels Molins se datan en el siglo IV y primera mitad del siglo III a. de C. y que no hay restos arquelógicos en la isla, en general, anteriores al siglo $\mathrm{V}$ a. de $\mathrm{C}$. (Blázquez, 1980: 338 y 465). También la temprana fecha dada para las cuentas gallonadas, datadas en la inhumación Bonjoan № 23 de Ampurias en los últimos años del siglo VI o primeros del V a. de C. (Almagro Basch, 1953: 136 y 165), queda atemperada en Mallorca y Menorca por la simultaneidad general con que aparecen los distintos modelos de cuentas. También se ha considerado que las cuentas decoradas con puntitos de pasta pegados son más antiguas que las polícromas en las que las pastas de distinto color están perfectamente fundidas sin diferencia de relieve (Almagro Basch, 1953: 310). Este posible indicador cronológico relativo tampoco se puede aplicar en las islas dada la mezcolanza de tipos de cuentas e, incluso, la convivencia de las dos técnicas sobre una misma cuenta (11).

\section{Cuentas metálicas (№ 72 y 73)}

De Son Bauzá proceden un colgante esférico y una cuenta de collar, ambos de bronce. Del primero, lo más parecido se encuentra en Cales Coves (Menorca), si bien son piezas de mucho menor tamaño y consistencia (Veny, 192: fig. 7 (22) y ss.).

Respecto a la cuenta de collar de bronce, las hay en otros yacimientos, como Son Maimó (Veny, 1977: fig. 6), aunque de menor tamaño. Suelen aparecer mezcladas con las de pasta, por lo que se consideran coetáneas. La cuenta de Son Bauzá № 73 tiene su réplica en la cuenta № 65 idéntica en forma y tamaño, pero realizada en pasta vítrea.

\section{Punzones (No 74 y 75)}

Ambos son de cobre o bronce, el primero es claramente un punzón bastante elaborado, mientras que del segundo no se puede asegurar categóricamente que lo sea.

\section{Aros simples y pequeña espiral (№ 76 a 78)}

Del tipo de anilla sencilla de sección redonda (No 78 ) se pueden encontrar buenos paralelos en Menorca, en particular en Cales Coves (Veny, 1982: 318), donde han aparecido en cuevas de distinta

(11) Véase la cuenta № 66 de Son Bauzá y otra de Cales Coves (Veny, 1982: fig. 115). 
cronología. Del segundo modelo con sección semicircular ( $\left.{ }^{2} 79\right)$, hay uno muy parecido en Son Cresta y varios más en Cales Coves. Por supuesto que estos no son los únicos, pero sí son los mejor documentados ya que, y esto puede hacerse extensivo a casi todos los materiales, el mal estado de conservación que suelen presentar y la poca precisión de las referencias bibliográficas hacen difícil la recopilación de paralelos exactos para estos objetos.

Lo mismo sucede con la pieza $\mathrm{N}^{2} 77$, una espiral de lámina de cobre o bronce que se puede considerar como un anillo o adorno para el pelo y del que conocemos un único paralelo hallado en Son Matge (Rosselló-Bordoy y Waldren, 1973: fig. 19 (13)) y cuya conservación en ambos casos puede considerarse excepcional.

\section{Cerámica decorada (№ 79)}

La cerámica incisa mallorquina ha sido dividida, con el consenso general de los investigadores, en dos tipos principales denominados incisa $A$ e incisa $B$. La forma casi exclusivamente utilizada por la primera es el cuenco hemiesférico y por la segunda el vaso troncocónico invertido; pareciendo, en cuanto a la decoración sobre todo, que la incisa $\mathrm{B}$ es una degradación de la incisa $\mathrm{A}$.

Además de estos dos tipos, se han encontrado algunos vasos de tipo globular propios de un momento más avanzado, con un tipo de decoración que no encaja con el resto de las cerámicas incisas. Hasta el presente son sólo casos aislados que no encuentran continuidad ni en los propios yacimientos de origen: Son Bauzá, Son Maiol y Es Corral des Porc (respectivamente: Cañigueral, 1952: 389 y Veny, 1962: 236; Cantarellas Camps, 1972: 46; Rosselló-Bordoy, 1962: 76-81).

El ejemplar de Son Bauzá, ha sido estudiado por C. Veny, que lo clasifica como forma $3 \mathrm{C}$ de la cerámica incisa B (Veny, 1968: 412). M. Fernández-Miranda lo ha considerado como forma 1d de la cerámica del Bronce Pretalayótico, con una cronología entre el 1800 y el 1300 a. de C. (FernándezMiranda, 1978: 159). C. Cantarellas Camps, por su parte, no acepta plenamente la relación entre el fragmento citado y los tipos de cerámica pretalayótica incisa conocidos en Mallorca (Cantarellas Camps, 1972).

Por una parte hay que reconocer que las formas globulares con asitas perforadas son sumamente características de la cultura pretalayótica, hasta el punto de estar consideradas como las más típicas de las halladas en cuevas artificiales de este período. Pero por otra parte, el ejemplar de Son Bauzá no responde muy exactamente a los tipos globulares pretalayóticos con los que se le quiere encuadrar. Si a pesar de todo su forma, sólo encuentra algún parecido con formas pretalayóticas, su decoración desde luego no; pero tampoco tiene parangón con cerámicas más modernas, con lo que esta curiosa ollita queda un tanto desconectada de lo hasta ahora conocido.

\section{Cerámica con asas de orejeta (№ 80$)$}

Este tipo de cerámica entra dentro de la variante $6 \mathrm{c}$ de la tipología del Talayótico II, con una cronología que abarca desde el año 700 a. de C. hasta la conquista romana (Fernández-Miranda; 1978: fig. 58). En Son Maimó se data entre los siglos IV y II a. de C. (Amorós, 1974: 165). Posteriormente, un análisis de $\mathrm{C} 14$ en el mismo yacimiento databa el nivel de estas cerámicas en el 420 a. de C., con una oscilación de 50 años (Veny, 1977: 154). Otros yacimientos (Cova Monja, Sa Carrotja) parecen evidenciar la pervivencia de estas formas hasta la época romana.

Ya L. Amorós señaló un posible reflejo de influencias helenísticas en la forma de estos vasos (Amorós, 1974: 166); si esto es así, el prototipo debió ser el skyphos con asas verticales o derivados de este. Lo cierto es que estas formas cerámicas con dos asas no tienen antecedentes en las Baleares ni en la época pretalayótica ni en la primera fase talayótica, en las que las asas prácticamente no existen; mientras que en el periodo Talayótico II hacen su aparición masiva los vasos con asas amplias que recuerdan formas comunes en el Mediterráneo durante la Edad del Hierro. 

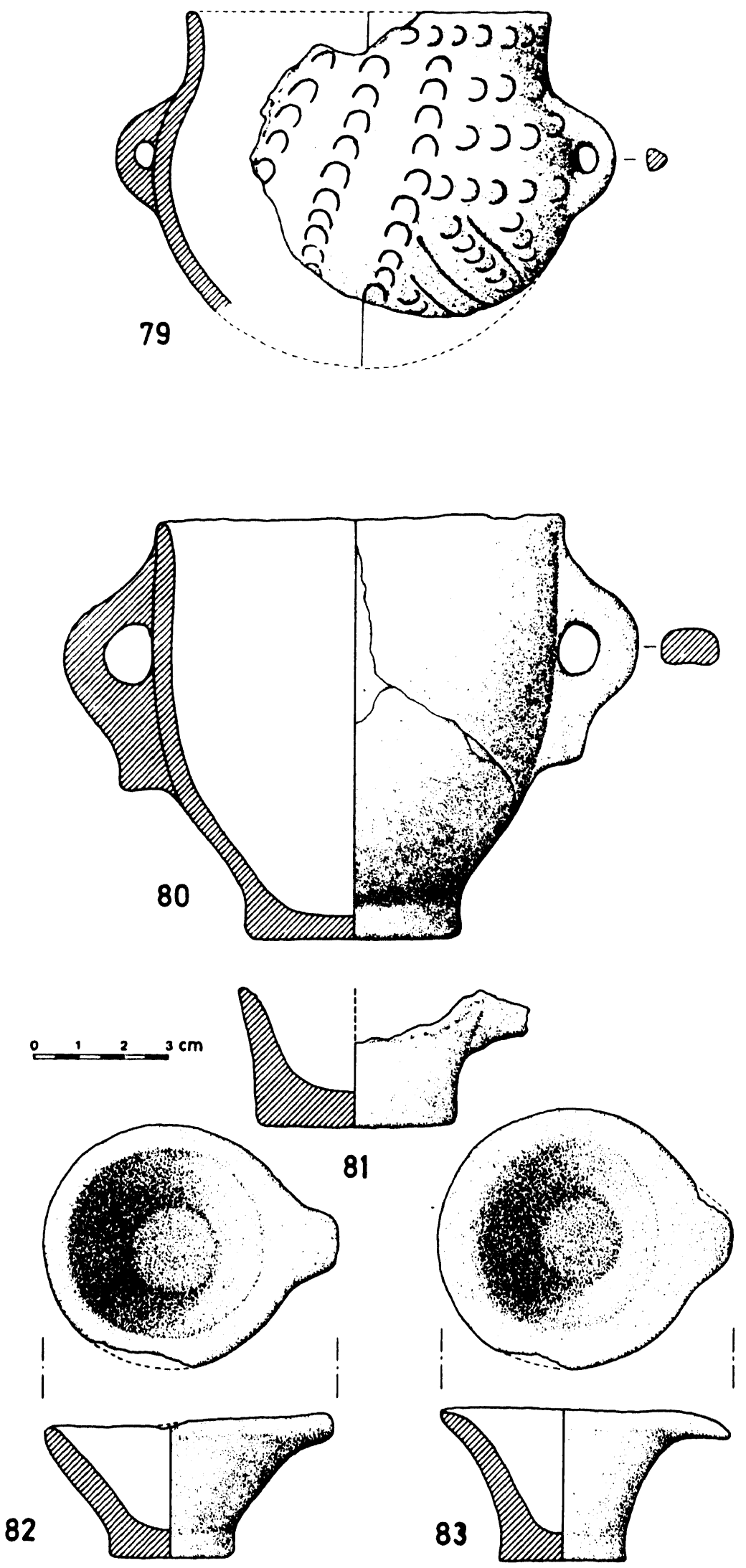

Fig. 12.-Cerámica.

T. P., 1991, $\mathrm{n}^{2} 48$

(c) Consejo Superior de Investigaciones Científicas

http://tp.revistas.csic.es Licencia Creative Commons 3.0 España (by-nc) 
Vasitos troncocónicos (№ 81-83)

En principio, este tipo de vasitos habían sido denominados funerarios por Maluquer basándose en las excavaciones de J. Colominas (Maluquer de Motes, 1975: 733). Sin embargo, la presencia en yacimientos muy dispares (poblados, necrópolis) hace pensar en una utilización más amplia que la puramente funeraria. J. Camps Coll y G. Rosselló-Bordoy sitúan estos vasitos dentro del tipo J de su clasificación, mientras que M. Fernández-Miranda los clasifica como 6a, dentro del Talayótico I, con una cronología que va del 1300 al 700 a. de C. (respectivamente: Camps Coll, 1969: 60 y ss.; RossellóBordoy, 1979: 162 y tabla III; Fernández-Miranda, 1978: 217).

\section{Cóndilos trabajados (№ 84 a 87)}

Una pieza muy característica en los yacimientos funerarios de la época final de la cultura talayótica es un códilo de fémur debastado mediante cortes longitudinales que dejan al descubierto la médula esponjosa del hueso y en la parte superior el casquete hemiesférico de la superficie articular. Con frecuencia presentan una perforación vertical.

El primer hallazgo documentado de estos objetos lo efectuó J. Colominas al excavar, en 1916 ó 1917 la cueva de Es Morro (Manacor). En su informe inventarió las piezas con el nombre de "taps" ya que se parecían a un tapón de botella; desde entonces esta denominación ha sido utilizada por casi todos los que han tratado el tema. Hasta ahora, el estudio más detallado sobre estos objetos es el de B. Font Obrador, que distingue tres tipos por su forma: tapón, hongo y falico (Font Obrador, 1969: 127), estando representados en Son Bauzá los tres tipos.

En cuanto a la procedencia zoológica del hueso en que están fabricados, ha habido diversidad de opiniones, pareciendo la más íundada la de que son de bóvido (Font Obrador, 1969: 133). Las
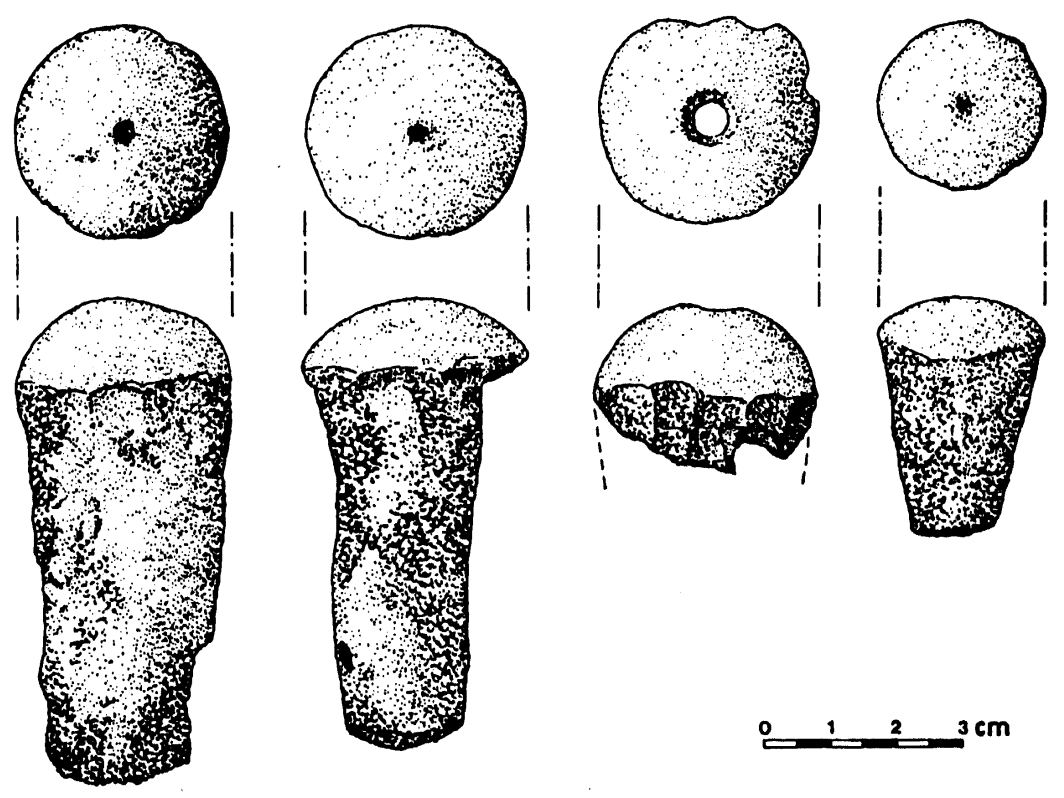

\section{$84-87$}

Fig. 13.-Cóndilos de fémur trabajados. 
teorías de que estos huesos sean, al menos en ocasiones, humanos, de cabra, oveja o cerdo carece de base científica en la bibliografía. Su interpretación también refleja diversidad de opiniones, colgantes o amuletos, remate ornamental de alguna espada o daga, pieza del ritual funerario, símbolo fálico... No estando ausente la interpretación relacionada con el posible culto taurolátrico que parecen reflejar otros elementos que también se encuentran en necrópolis: vértebras caudales de toro y figuritas representando a este animal (Veny, 1982: 368).

\section{EL RITO FUNERARIO}

Tanto la cueva de Son Bauzá como otras a las que venimos aludiendo, debieron tener por lo general un dilatado periodo de utilización como necrópolis llegando en algunos casos hasta épocas contemporáneas del dominio romano de las islas. Esto es, sin duda, la causa que hace que aparezcan en los niveles superiores o superficiales de muchas de estas necrópolis restos cerámicos característicos del mundo comercial romano (campaniense, sigillata, paredes finas, etc.); como también incineraciones en urnas de piedra local (marés) como en Son Bosc, Sa Madona, Sa Moleta, Son Serra y Son Boronat (Enseñat Enseñat, 1981: 30 y Veny, 1982: 393), e incluso una urna de cerámica con tapadera recogida en Cova Monja (Colominas, 1920b: fig. 592).

Dejando aparte estas consecuencias del influjo o aculturación romanos que confundieron a J. Colominas y le hicieron calificar estas necrópolis como "cuevas romanas de enterramiento" (Colominas, 1920b), señalaremos que la característica fundamental y más peculiar de estos conjuntos funerarios es la utilización masiva de cal en los enterramientos.

\section{Incineración o inhumación}

Desde que J. Colominas publicara el resumen de sus investigaciones en Mallorca en el Anuari de l'Institut d'Estudis Catalans (Colominas, 1920b; 728-735), sus opiniones sobre la existencia de incineraciones, cremaciones o inhumaciones en diversos yacimientos fueron el caldo de cultivo para la polémica entre los que interpretaban que estos enterramientos fueron realizados con uno u otro sistema. Parece ser que J. Colominas a fines de la década de los cuarenta había aceptado las tesis de los que opinaban a favor de la inhumación como rito único anterior a la romanización; pero no llegó a expresar esto en ninguna publicación y la discrepancia sobre el tema perduró hasta la década de los setenta (Enseñat, 1974: 130 y Font Obrador, 1974: 47).

En cuanto al rito funerario utilizado en Son Bauzá, las únicas noticias son las proporcionadas por L. Lliteras y L. Amorós. El primero alude a "enterramientos incinerados" (Lliteras, 1929) y el segundo a "enterramientos de incineración" (Amorós, 1929: 290-291). Sin duda ambos seguían los criterios impuestos por J. Colominas, predominantes en aquellos años, ya que el mismo L. Amorós cita en un trabajo posterior la cueva de Son Bauzá entre las cuevas mallorquinas con «inhumaciones colectivas" (Amorós, 1952: 2). Ni Lliteras, ni Amorós mencionan nada acerca del uso de cal en los enterramientos de Son Bauzá, si bien Amorós señala la existencia de "cenizas blancas» en el nivel arqueológico fértil (Amorós, 1929: 290). Estas cenizas, opinamos deben corresponder al aspecto que ofrecía la cal de la que quedaban abundantes restos adheridos a todos los restos óseos humanos de este yacimiento estudiados por M. ${ }^{a}$ D. Garralda (1975: 93), que además no apreció ningún síntoma de incineración en dichos restos. También apreciamos, en su día, restos de cal sobre la espada número 7 y brazaletes números 10,13,23, 24 y 25 que publicamos en este artículo.

C. Veny sostiene que simultáneamente a la introducción del uso de la cal para los enterramientos aparece "junto al rito de la inhumación, el rito de la cremación y posteriormente el de la incineración. Se alternarían inhumaciones con cal con cremaciones (incineraciones incompletas), quedando la 
incineración para las últimas etapas de la prehistoria y la época romana. Según C. Veny, se pueden observar los efectos de la cremación en algunos restos de ajuar y huesos. La pira funeraria pudo estar en ocasiones en el interior de las cuevas de lo que quedarían huellas en las bóvedas de algunas de ellas (Veny 1982: 391-393).

\section{Inhumaciones con cal}

La investigación actual considera como definitorio de estas necrópolis, en cuanto al rito funerario, la inhumación con cal. La cal utilizada era presumiblemente cal viva. Para obtener este producto es necesario someter piedras calizas - abundantísimas en Mallorca y Menorca - a una temperatura prolongada hasta alcanzar los 900 ó 1000 grados centígrados.

No hay evidencia arqueológica de los hornos u otros procedimientos usados por los antiguos baleares para producir la cal; ni sabemos si fue un procedimiento autóctono o importado. Conocedores de la metalurgia del hierro y otros metales, no les eian extrañas las tecnologías para lograr altas temperaturas, necesarias en la calcinación. En algunas cuevas aparecen grandes cantidades de cal apagada, aparentemente almacenada y dispuesta para su utilización en los enterramientos (Enseñat Enseñat, 1976: 68 y 1981: 144 y ss.).

Parece ser que en el momento de practicar una inhumación se arrojaba sobre el cadáver depositado quizá en un pequeño hoyo junto con su ajuar, una cantidad suficiente de cal viva - pura o mezclada con tierra y piedras - como para cubrir por completo el cadáver (Veny, 1982: 390-391).

La cronología de este uso de la cal, arrancaría de fines del siglo VII o principios del VI a. de C., coincidiendo más o menos con la introducción del hierro en las islas; y se generalizaría, aunque no de una manera absoluta, avanzada la romanización (Veny, 1982: 381 y ss.).

\section{Posición de los inhumados}

De igual forma que faltan referencias claras acerca de la existencia de cal en cuevas que, sin embargo, debieron tenerla dadas las semejanzas de sus ajuares con los de otras en las que la utilización de la cal está bien documentada; también es escasa la información sobre la posición y orientación que adoptan los cadáveres allí depositados. Los datos relativos al número, sexo y edad de los alli enterrados son prácticamente inexistentes en la bibliografía. Están documentados enterramientos en posición fetal, probablemente con las extremidades fuertemente atadas sobre el cuerpo y apoyados de costado sobre el suelo o dentro de sarcófagos de madera.

\section{Sarcófagos de madera}

En la cueva de Son Maimó; L. Amorós excavó una necrópolis que proporcionó una gran variedad de restos de madera: parihuelas, cajas, ataúdes, etc. (Amorós, 1974).

En la excavación de la cueva de Son Bauzá ya se habían apreciado restos de madera carbonizada (Amorós, 1929: 290-292), pero como reconocería Amorós años más tarde, con motivo de la publicación de la excavación de Son Maimó: "no imaginábamos entonces ni supimos advertir la existencia de ataúdes, quizá debido principalmente a las deficientes condiciones de luz con que se realizaban los trabajos en el interior de las cuevas (Amorós, 1974; 159).

Paralelos para estos ataúdes son los cinco de la Cometa dels Morts (Veny, 1981: 261), los de Son Boronat (Guerrero, 1979), Cales Coves (Veny, 1982: 368) y quizás los hubo también en Cova Monja (Colominas, 1920b: 731). 
- (1961): «Contribuciones a la Geología de Mallorca». Boletin de la Sociedad de Historia Natural Balear, VII: 31 y SS.

Blázoufz, J. M. (1960): «Recipientes de bronce del Museo Arqueológico Nacional de Madrid». Archivo Español de Arqueología, XXXIII, Madrid: 197-210.

Blázouez, J. M., Presedo, F., Lomas, F. J. y Fernández-Nieto, J. (1980): «Historia de España Antigua. I. Protohistorian. Ed. Cátedra. Madrid.

Bosch-Gimpera, P. (1954): «La Edad del Bronce de la Península Ibérica». Archivo Español de Arqueologia, XXVII: 45-92.

Camps Coll, J. (1969): Notas para una tipología de la cerámica talayótica mallorquina. Trabajos del Museo de Mallorca, 6.

Cantarellas Camps, C. (1972): "Cerámica incisa de Mallorcom. Palma de Mallorca.

Cañigueral, J. (1952): «Más sobre Sa Canova de Ariany». Ibérica, 233. Barcelona: 3-8.

CINTAS, P. (1976): «Manuél d'archéologie puniquen, I-I, París.

Colominas Roca, J. (1920a): «L'Edat del Bronze a Mallorca. Les investigacions de L'Institut (1916-1920)». Anuari de l'Institut d'Estudis Catalans, VI. Barcelona: 555-573.

- (1920b): "Coves romanes d'enterrament a Mallorca». Anuari de l'Institut d'Estudis Catalans, VI. Barcelona: 728-735.

CUADRADO, E. (1963): «Precedentes y prototipos de la fibula anular hispana». Trabajos de Prehistoria, VII: 7-61.

DaremberG-SaGlo (1969): «Dictionnaire des Antiquites, II/1: 277-280, voz: «Discus»; V: 341-343, voz: "Tintinnabulum».

Dechelette, J. (1913): Manuel d'Archéologie Prehistorique, Celtique et Gallo-Romaine, II. Archaéologie Celtique ou protohistorique; Deuxiéme partie: Premier Age du Fer ou époque de Hallstatt. París.

ENSEÑAT ENSEÑAT, C. (1976): Las plaquetas de plomo mallorquinas. Trabajos del Museo de Mallorca, 19.

- (1981): Las cuevas sepulcrales mallorquinas de la Edad del Hierro. Excavaciones Arqueológicas en España, 118. Ministerio de Cultura. Madrid.

Enseñat Estrany, B. (1971): «Historia Primitiva de Mallorca». En J. Mascaró Pasarius (coord.): «Historia de Mallorcas. Palma de Mallorca: 308 y ss.

Fernández Miranda, M. (1978): Secuencia cultural de la prehistoria de Mallorca. Bibliotheca Praehistorica Hispana, XV. CSIC. Madrid.

FonT OBRADOR, B. (1969): «El ciclo cultural prerromano balear. El espécimen hueso tallado en las necrópolis de Mallorca y Menorcam. Actas del X Congreso Nacional de Arqueologia (Mahón, 1967): 127-135. Zaragoza.

- (1970): «Mallorca protohistórica». En J. Mascaró Pasarius (coord).: "Historia de Mallorca». Palma de Mallorca: 353-416.

- (1974): «La obra de Josep Colominas en Mallorca». VI Symposium de Prehistoria Peninsular. Barcelona: 39 51.

Garralda, M. ${ }^{a}$ D. (1975): «Estudio antropológico de la cueva de Son Bauzá (Mallorca)». Trabajos de Prehistoria, 32: 93-112.

Delibes De Castro, G. y Fernández-Miranda, M. (1988): Armas y utensilios de bronce en la Prehistoria de las Islas Baleares. Studia Archaeologica, 78. Universidad de Valladolid.

Guerrero, V. (1973): «El yacimiento funerario de Son Boronat (Calviá-Mallorca)». Boletín de la Sociedad Arqueológica Luliana, 37. Palma de Mallorca: 1-58.

Hus, A. (1975): «Les Bronces Etrusques». Collection «Látomus», 139. Bruxelles.

Lliteras, L. (1929): "¿La cultura de Hallstat en Mallorca?». Correo de Mallorca (29 de mayo). Palma de Mallorca: sin pág.

MaluQuer De Motes, J. (1975): «La Edad del Bronce de las Islas Baleares». En Menéndez Pidal (dir.) «Historia de Españan, I, España Prehistórica, I, V. Madrid: 715-751.

Mascaró Pasarius, J. (1968): «Prehistoria de las Baleares. Palma de Mallorca.

MoNTELIUS, O. (1895): «La civilisation primitive en Italie depuis l'introduction des métaux. Estocolmo. (Reimpresión de 1910).

Mulet, A. (1952): «Mallorca. Ca'n Mulet de Génova». Palma de Mallorca.

MULLER-KARPE, H. (1966): «Handbuch der Vorgeschichten. München.

Pallotino, M. (1956): «Etruskische Kunst». Zürich.

PERICOT, L. (1972): «The Balearic Islands». Londres.

RichTER, G. M. A. (1980): «El Arte Griego». Traducción de «A Handbook of Greek Art» (1959). Barcelona.

ROSELlÓ-BoRDOY, G. (1974): «Los ajuares metálicos mallorquines como elemento cronológico». VI Simposium de Prehistoria Peninsular. Barcelona: 115-127. 
- (1979): "La cultura Talayótica en Mallorcan. Palma de Mallorca. 2." Ed.

ROSSEllo-BordoY, G. y WALDREN, W. (1973): „Excavaciones en el abrigo del bosque de Son Matge (Valdemossa, Mallorca)». Noticiario Arqueológico Hispánico, Prehistoria, II: 7-16.

SCHULE, W. (1960): «Frühe Antennenwaffen in Südwesteuropa». Germania, 38: 1-19.

- (1969): Die Meseta-Kulturen der Iberischen HalbinseL Madrider Forchungen, 3. Instituto Arqueológico Alemán de Madrid. Berlín.

VenY, C. (1947): "La necrópolis de la cueva de "Cometa dels Morts", cerca de Lluch, en Mallorca». Archivo Español de Arqueología, XX: 45-59.

- (1950): "La necrópolis de la cueva de "Sa Cometa dels Morts", cerca de Lluch (Mallorca)». Archivo Español de Arqueologia, XXIII: 319-328.

- (1968): Las cuevas sepulcrales del Bronce Antiguo de Mallorca. Bibliotheca Praehistorica Hispana IX. CSIC. Madrid.

- (1977): «Apuntes complementarios sobre la cueva de la Edad del Hierro de Son Maimó, Petra (Mallorca)». Trabajos de Prehistoria, 34: 111-164.

- (1981): «El complejo funerario de una galeria subterránea de la Cometa dels Morts, Lluc, Escorca (Mallorca)». Trabajos de Prehistoria, 38: 257-276.

- (1982): La necrópolis protohistórica de Cales Coves (Menorca). Bibliotheca Praehistórica Hispana, XX. CSIC. Madrid.

- (1983a): «Cueva II de la Cometa dels Morts (Escorca, Mallorca)». Noticiario Arqueológico Hispánico, 15: 341358.

- (1983b): «Cova Murada (Barranco de Algendar, Menorca)». Noticiario Arqueológico Hispánico, 15: $383-402$.

- (1983c): "La cultura de las cerámicas incisas en Mallorca». Homenaje al Profesor Martín Almagro Basch, II: 185-191.

VIVES y ESCUDERO, A. (1917): «Estudios de Arqueología Cartaginesa. La Necrópolis de Ibizan. Madrid.

Waldren, W. (1982): Balearic Prehistoric Ecology and Culture. The excavation and study of certain caves, rock shelter and settlements. British Archeological Report Internacional Series, 149 (II). Oxford. 